\title{
Developmental Synaptic Changes at the Transient Olivocochlear-Inner Hair Cell Synapse
}

\author{
[CGraciela Kearney, ${ }^{1 *}$ - Javier Zorrilla de San Martín, ${ }^{1 *}$ - Lucas G. Vattino, ${ }^{1}$ Ana Belén Elgoyhen, ${ }^{1,2}$ \\ [Carolina Wedemeyer, ${ }^{1}$ and ${ }^{-E}$ Eleonora Katz ${ }^{1,3}$ \\ ${ }^{1}$ Instituto de Investigaciones en Ingeniería Genética y Biología Molecular, Dr. Héctor N. Torres, Consejo Nacional de Investigaciones Científicas y Técnicas, \\ 1428 Ciudad Autónoma de Buenos Aires, Argentina, ${ }^{2}$ Instituto de Farmacología, Facultad de Medicina, Universidad de Buenos Aires, 1121 Ciudad \\ Autónoma de Buenos Aires, Argentina, and ³Departamento de Fisiología, Biología Molecular y Celular, Facultad de Ciencias Exactas y Naturales, \\ Universidad de Buenos Aires. Ciudad Universitaria, C1428EGA Ciudad Autónoma de Buenos Aires, Argentina.
}

In the mature mammalian cochlea, inner hair cells (IHCs) are mainly innervated by afferent fibers that convey sound information to the CNS. During postnatal development, however, medial olivocochlear (MOC) efferent fibers transiently innervate the IHCs. The MOC-IHC synapse, functional from postnatal day 0 (P0) to hearing onset (P12), undergoes dramatic changes in the sensitivity to acetylcholine (ACh) and in the expression of key postsynaptic proteins. To evaluate whether there are associated changes in the properties of ACh release during this period, we used a cochlear preparation from mice of either sex at P4, P6 - P7, and P9-P11 and monitored transmitter release from MOC terminals in voltage-clamped IHCs in the whole-cell configuration. The quantum content increased 5.6 $\times$ from P4 to P9-P11 due to increases in the size and replenishment rate of the readily releasable pool of synaptic vesicles without changes in their probability of release or quantum size. This strengthening in transmission was accompanied by changes in short-term plasticity properties, which switched from facilitation at $\mathrm{P} 4$ to depression at P9-P11. We have previously shown that at P9-P11, ACh release is supported by $\mathrm{P} / \mathrm{Q}-$ and $\mathrm{N}$-type voltage-gated calcium channels (VGCCs) and negatively regulated by BK potassium channels activated by $\mathrm{Ca}^{2+}$ influx through L-type VGCCs. We now show that at P4 and P6-P7, release is mediated by P/Q-, R- and L-type VGCCs. Interestingly, L-type VGCCs have a dual role: they both support release and fuel BK channels, suggesting that at immature stages presynaptic proteins involved in release are less compartmentalized.

Key words: BK channels; cochlear hair cells; MOC efferent synapses; synaptic plasticity; synaptic transmission; voltage-gated calcium channels

Significance Statement

During postnatal development before the onset of hearing, cochlear inner hair cells (IHCs) present spontaneous Ca ${ }^{2+}$ action potentials that release glutamate at the first auditory synapse in the absence of sound stimulation. The IHC $\mathrm{Ca}^{2+}$ action potential frequency pattern, which is crucial for the correct establishment and function of the auditory system, is regulated by the efferent medial olivocochlear (MOC) system that transiently innervates IHCs during this period. We show here that developmental changes in synaptic strength and synaptic plasticity properties at the MOC-IHC synapse upon MOC fiber activation at different frequencies might be crucial for tightly shaping the pattern of afferent activity during this critical period.

\section{Introduction}

In the mammalian cochlea, sounds are converted into electrical signals by mechanosensory cells: inner and outer hair cells (IHCs

\footnotetext{
Received Oct. 22, 2018; revised Jan. 4, 2019; accepted Jan. 30, 2019.

Author contributions: G.K., J.Z.d.S.M., L.G.V., and C.W. performed research; G.K., J.Z.d.S.M., L.G.V., and C.W. analyzed data; A.B.E. and E.K. designed research; A.B.E., C.W., and E.K. edited the paper; E.K. wrote the paper.

This work was supported by the Agencia Nacional de Promoción Científica y Tecnológica, Argentina (A.B.E. and E.K.), the University of Buenos Aires (E.K. and A.B.E.), and the National Institutes of Health (Grant R01 DC001508 to Paul A. Fuchs and A.B.E.).

The authors declare no competing financial interests.

${ }^{*} G$.K. and J.Z.d.S.M. contributed equally to this work.
}

and OHCs, respectively). IHCs convey these signals to the CNS, whereas OHCs are involved in the amplification and fine tuning of sounds (Hudspeth, 1997). Sound processing in the cochlea is modulated by descending efferent fibers of the medial olivocochlear system (MOC) (Guinan, 2011). In the mature mammalian cochlea, IHCs are mainly innervated by afferent fibers regulated by a descending efferent innervation from the lateral olivoco-

\footnotetext{
J. Zorrilla de San Martín's present address: Institut du Cerveau et de la Moelle épinière - ICM Paris, France. Correspondence should be addressed to Eleonora Katz at eleokatz@gmail.com or ekatz@dna.uba.ar. https://doi.org/10.1523/JNEUROSCI.2746-18.2019

Copyright $\odot 2019$ the authors
} 
chlear system (LOC) (Liberman et al., 1990; Guinan, 2011). However, during postnatal development, before the onset of hearing at postnatal day 12 (P12) in altricial rodents, MOC fibers transiently innervate the IHCs (Glowatzki and Fuchs, 2000; Katz et al., 2004; Roux et al., 2011) even before contacting their final targets, the OHCs (Liberman et al., 1990; Simmons et al., 1996; Simmons, 2002). Several studies suggest that this transient efferent innervation plays a role in the ultimate functional maturation of cochlear hair cells (Simmons, 2002) and in the correct establishment of the auditory pathway by regulating the spontaneous IHC firing frequency during this critical developmental period (Glowatzki and Fuchs, 2000; Goutman et al., 2005; Johnson et al., 2013; Sendin et al., 2014; Moglie et al., 2018; Wedemeyer et al., 2018). This notion is reinforced by the observation that mice that lack functional efferent MOC-hair cell synapses present a decreased tonotopic organization in the lateral superior olive and a concomitant impairment in the detection of sound frequency changes (Clause et al., 2014, 2017).

The postsynaptic events at MOC-hair cell synapses are well characterized, namely the activation of calcium-permeable $\alpha 9 \alpha 10$ nicotinic acetylcholine (ACh) receptors (nAChRs) (Elgoyhen et al., 1994, 2001; Elgoyhen and Katz, 2012) leads to the opening of calcium-dependent $\mathrm{K}^{+}$channels that hyperpolarize the hair cells (Dulon and Lenoir, 1996; Glowatzki and Fuchs, 2000; Oliver et al., 2000; Katz et al., 2004, 2011; Wersinger et al., 2010; Wersinger and Fuchs, 2011). In mammals, fast synaptic transmission at both central and peripheral synapses is mediated by multiple types of voltage-gated calcium channels (VGCCs), including N-, P/Q-, and R-type channels (Katz et al., 1997; Plant et al., 1998; Reid et al., 2003; Catterall and Few, 2008). VGCCs are formed by at least four different subunits $(\alpha 1, \alpha 2-\delta, \beta$, sometimes also $\gamma$ ). The biophysical and pharmacological diversity of VGCCs, classified into L, P/Q, N, R, and T types, arises from the existence of multiple pore-forming $\alpha 1$ subunits (Catterall, 1998; Catterall and Few, 2008). In the mouse cochlea, expression of the $\alpha 1$ subunits $\mathrm{Ca}_{\mathrm{v}} 1.2$ (L-type), $\mathrm{Ca}_{\mathrm{v}} 1.3$ (L-type), and $\mathrm{Ca}_{\mathrm{v}} 2.3$ (Rtype) has been shown by PCR analysis (Green et al., 1996).

The MOC-IHC synapse undergoes dramatic changes in innervation pattern, sensitivity to $\mathrm{ACh}$, and expression of key postsynaptic proteins (Glowatzki and Fuchs, 2000; Simmons, 2002; Katz et al., 2004; Roux et al., 2011). In developing synapses, synaptic modifications likely take place concurrently in both postsynaptic cells and presynaptic terminals. Therefore, $\mathrm{Ca}^{2+}$ channels subtypes coupled to the release process are developmentally regulated both at central synapses (Iwasaki et al., 2000; Momiyama, 2003; Fedchyshyn and Wang, 2005) and at the neuromuscular junction (NMJ) (Rosato Siri and Uchitel, 1999). We have previously shown that, at MOC-IHC synapses from P9P11 mice, ACh release is supported by both P/Q- and N-type VGCC and negatively regulated by BK potassium channels activated by $\mathrm{Ca}^{2+}$ entry through L-type VGCC (Zorrilla de San Martín et al., 2010). In this work, we investigated presynaptic changes that shape the maturation of the MOC-IHC synapse by analyzing the strength of ACh release, the short-term plasticity (STP) pattern, and the types of VGCC coupled to the release process at three postnatal ages P4, P6-P7, and P9-P11. We describe developmental changes in all the above-mentioned parameters that might be crucial for tightly shaping the pattern of afferent activity during the establishment of the auditory pathway before hearing onset.

\section{Materials and Methods}

Animal procedures and isolation of the organ of Corti. Procedures for preparing and recording from the postnatal mouse organ of Corti were essentially identical to those published previously (Zorrilla de San Martín et al., 2010). Briefly, apical turns of the organ of Corti were excised from Balb/C mice of either sex at three postnatal stages, P4, P6-P7, and P9P11 (day of birth was considered P0) and used within $3 \mathrm{~h}$. Cochlear preparations were placed in the chamber for electrophysiological recordings, mounted under a Leica DMLFS microscope, and viewed with differential interference contrast (DIC) using a $40 \times$ water-immersion objective and a camera with contrast enhancement (Hamamatsu, C7500-50). All experimental protocols were performed in accordance with the American Veterinary Medical Associations' AVMA Guidelines on Euthanasia (2013 Edition).

Electrophysiological recordings. IHCs were identified visually and by the size of their capacitance $(7-12 \mathrm{pF})$. The cochlear preparation was continuously superfused by means of a peristaltic pump (Gilson Minipulse 3 with 8 channels; Bioesanco) containing an extracellular saline solution of an ionic composition similar to that of the perilymph (in mM): $144 \mathrm{NaCl}$, $5.8 \mathrm{KCl}, 1.3 \mathrm{CaCl}_{2}, 0.7 \mathrm{NaH}_{2} \mathrm{PO}_{4}, 5.6 \mathrm{D}$-glucose, and 10 HEPES buffer, $\mathrm{pH}$ 7.4. Working solutions containing the different drugs and toxins used were made up in this same saline and delivered through the perfusion system. The pipette solution contained the following (in $\mathrm{mM}$ ): $140 \mathrm{KCl}$, 3.5 $\mathrm{MgCl}_{2}, \quad 0.1 \quad \mathrm{CaCl}_{2}, \quad$ glycol-bis(2-aminoethylether)-N,N,N', $\mathrm{N}^{\prime}$ tetraacetic acid (5 mM EGTA), 5 HEPES buffer, and $2.5 \mathrm{Na}_{2}$ ATP, pH 7.2. Some cells were removed to access IHCs, but mostly the pipette moved through the tissue using positive fluid flow to clear the tip. Currents in IHCs were recorded in the whole-cell patch-clamp mode using an Axopatch 200B amplifier, low-pass filtered at $2-10 \mathrm{kHz}$ and digitized at 5-20 $\mathrm{kHz}$ with a Digidata 1322A board (Molecular Devices). Recordings were made at room temperature $\left(22-25^{\circ} \mathrm{C}\right)$. Glass pipettes, $1.2 \mathrm{~mm}$ inner diameter, had resistances of $4-7 \mathrm{M} \Omega$. Indicated holding potentials were not corrected for liquid junction potentials $(-4 \mathrm{mV})$. Unless otherwise stated, IHCs were voltage clamped at a holding voltage of $-90 \mathrm{mV}$. As control of IHC viability before studying transmitter release at the MOCIHC synapse, once in the whole-cell configuration just after break-in, voltage protocols were applied to determine whether the amplitude and kinetics of the outward-voltage-dependent currents looked like those described in neonatal IHCs (Marcotti et al., 2003).

Electrically evoked transmitter release. Neurotransmitter release was evoked by extracellular electrical stimulation of MOC efferent axons. Briefly, the electrical stimulus was delivered to the efferent axons via a glass pipette $(0.4-0.9 \mathrm{M} \Omega$ resistance) placed at $\sim 80-100 \mu \mathrm{m}$ modiolar to the base of the IHC under study. The position of the pipette was adjusted until postsynaptic currents obtained by voltage-clamping the IHC in the whole-cell configuration were consistently activated. The only data on the number of MOC-IHC functional synaptic contacts at the MOC-IHC transient synapse is that found in Moglie et al. (2018). By doing minimal-maximal electrical stimulation of the efferent fibers in mice at P9-P11, they report at most 2-8 (average 5.9) MOC-IHC synaptic contacts per IHC, which can be sequentially activated upon increasing the stimulus strength. Whether each one of them is composed by one or more active zones has not been determined. Moreover, it is not known whether these synaptic contacts come from one axon that branch to several active zones or if there are multiple axons contacting the IHC. Furthermore, there are no reports on the number of synaptic contacts per IHC at the earlier stages (P4 and P6-P7) of development. Therefore, at all ages and in all cases, we always used the minimal electrical stimulation necessary to be sure we obtained a reproducible postsynaptic response time-coupled to the stimulus. A Grass stimulator (model S48 stimulator coupled to a SIU5 isolation unit) was triggered via the data acquisition computer to generate pulses up to 70-300 $\mu \mathrm{A}, 0.1-0.2 \mathrm{~ms}$.

Transmitter release evoked by high extracellular $\mathrm{K}^{+}$. Neurotransmitter release from efferent terminals was elicited by depolarization using 15-25 $\mathrm{mm}$ external potassium saline applied by a bath perfusion system (rate flow $2 \mathrm{ml} / \mathrm{min}$ ). Spontaneous IPSCs (sIPSCs) were identified by eye using MiniAnalysis (RRID:SCR_002184). After incubation of the preparation in high $\mathrm{K}^{+}(15-25 \mathrm{~mm})$ solution for 4-8 $\mathrm{min}$, either an L-type VGCC 
antagonist, nifedipine (Nife, $3 \mu \mathrm{M})$, or an agonist, Bay-K (10 $\mu \mathrm{M})$, was applied through the bath perfusion system. To quantify the effects of each drug, sIPSC frequency was determined after $15 \mathrm{~min}$ of incubation with either Nife or Bay-K and compared with sIPSC frequency in high $\mathrm{K}^{+}$ solution without drugs.

Estimation of the quantum content of transmitter release. The quantum content of transmitter release $(m)$ was estimated by two methods. The first method was the "direct method," the ratio between the mean amplitude of evoked IPSCs (eIPSCs) and the mean amplitude of sIPSCs (Del Castillo and Katz, 1954a). To estimate eIPSC mean amplitude (failures of release are included in this estimation), protocols of 100 stimuli were applied at a frequency of $1 \mathrm{~Hz}$. Spontaneous synaptic currents were recorded during the stimulation protocol. Under the assumption that evoked synaptic events followed a Poisson distribution, $m$ was also calculated by the second method, the "method of failures" $\left(m=\ln \left(N / N_{0}\right)\right.$, where $N$ is the total number of stimuli and $N_{0}$ the number of failures (Del Castillo and Katz, 1954a). To quantify the effects of each drug or toxin used to evaluate the coupling of the different VGCCs and BK potassium channels to the release process, the preparation was incubated for the time necessary to reach a plateau for the observed effect. Dihydropyridine (DHP), iberiotoxin (IbTx), and SNX-482 (SNX) reached a plateau after 5 min of incubation; so 3 measurements at 5, 7.5, and 10 min after their application to the bath were averaged. Omega-agatoxin ( $\omega$-Aga) IVA reached the plateau after $10 \mathrm{~min}$ of incubation, so 3 measurements at $10,12.5$, and $15 \mathrm{~min}$ after its application to the bath were averaged. In the case of $\omega$-conotoxin ( $\omega$-CgTx) GVIA, the plateau was reached after 20 min of incubation, so 3 measurements at 20,22.5, and 25 min after its application to the bath were averaged. Percentage quantum content $(\% m)$ was calculated as follows: $m_{t} / \bar{m}_{c}{ }^{\star} 100$, where $\bar{m}_{c}$ is the estimation of $m$ mean in the control condition and $m_{\mathrm{t}}$ is the quantum content estimated after incubation of the preparation with the drug or toxin under study. Synaptic currents were analyzed with MiniAnalysis and with custom routines implemented in Igor Pro 6.0 (Wavemetrics, RRID: SCR_000325).

It must be taken into account that we refer to postsynaptic currents as "inhibitory" even though, at $-90 \mathrm{mV}$, the patch-clamp voltage used in all our experiments, they are inward and therefore depolarizing or "excitatory." However, at the IHC physiological membrane potential ( -60 $\mathrm{mV}$ or even more depolarized), postsynaptic currents due to ACh release are inhibitory. Inhibition arises because the activation of calciumpermeable $\alpha 9 \alpha 10$ nAChRs (Elgoyhen et al., 1994, 2001) leads to the opening of calcium-dependent SK2 $\mathrm{K}^{+}$channels that hyperpolarize the IHCs (Glowatzki and Fuchs, 2000; Katz et al., 2004; Gómez-Casati et al., 2005; Roux et al., 2011). Under our recording conditions, the potassium reversal potential is $-82 \mathrm{mV}$, so at $-90 \mathrm{mV}$, currents through both nAChRs and SK2 channels are inward (see Fig. $1 A$ in Gómez-Casati et al., 2005). We chose to voltage clamp the IHCs at $-90 \mathrm{mV}$ because they are much more stable and remain healthier for longer times at this voltage than at more depolarized potentials.

Estimation of STP. The STP pattern was studied applying 10-80 repetitions of 10-pulse stimulation trains at 10,40 , and $100 \mathrm{~Hz}$ at 15 (for 10 $\mathrm{Hz}$ trains) or $20 \mathrm{~s}$ intervals (for 40 and $100 \mathrm{~Hz}$ trains). For every pulse, the current amplitude was computed as the difference between the peak of the response and the baseline, which was considered as the current value before the pulse. The probability of successfully evoking a release event $\left(P_{\text {success }}\right)$ for each pulse was computed as the ratio between the number of eIPSCs and the number of sweeps. The average amplitude $(A)$ was obtained by averaging the successful eIPSCs amplitudes after each pulse. The overall amplitude $(S)$ for each stimulus was computed as the average of all recorded amplitudes, including failures of response. To establish the extent of facilitation or depression during a train, the values for the parameters $S, P_{\text {success }}$, and $A$ for each pulse were compared with the value at the first pulse.

Estimation of the readily releasable pool of vesicles (RRP) parameters. The RRP size and the replenishment rate were estimated by the method established by Schneggenburger et al. (1999) based on the use of highfrequency stimulation trains to exhaust the synapse and reach a stationary state in which only newly recruited vesicles are released (see Fig. $5 d-f$ ). This method assumes that replenishment is constant during the train; it does not assume that all vesicles have the same initial probability and does not require that it remains constant during the train (Schneggenburger et al., 1999; Neher, 2015).

Train stimulation protocols composed of 50 pulses at $100 \mathrm{~Hz}$ were repeated 10-30 times at $20 \mathrm{~s}$ intervals. The cumulative amplitude mean was plotted as a function of stimulus number and the stationary region was fitted to a linear function. The cumulative amplitude mean of eIPSCs at the $i^{\text {th }}$ pulse was calculated as follows:

$$
A(i)=\sum_{0}^{x=i} \bar{A}(x)
$$

Where $\bar{A}(x)$ is the cumulative amplitude mean of the IPSCs evoked by the $x^{\text {th }}$ pulse of the train. To guarantee that the stationary region of the cumulative plot had been considered, the linear fit was calculated on the cumulative amplitudes of the last 20 pulses of the train. In this region, the plots of cumulative amplitudes of all recorded cells showed a linear behavior. The intercept of this fit divided by the quantum size (the mean sIPSC amplitude) corresponds to the number of vesicles that were ready to be released at the beginning of the stimulation train. The slope of the same fit divided by the quantum size and multiplied by the stimulation frequency corresponds to the replenishment rate expressed as number of vesicles/s. By calculating the ratio between the average number of vesicles released per action potential (quantum content) and the number of vesicles ready to be released (RRP size), the probability of each vesicle to be released $\left(P_{\text {vesicle }}\right)$ was obtained for each cell. For an extensive discussion of the method and its advantages and limitations and comparison with other methods, see Neher (2015).

Statistics. All statistical tests were performed with RStudio 1.1.442 (RRID:SCR_000432) (R Core Team, 2008) except for two-way ANOVA, which was performed with GraphPad Prism 6.01 (RRID:SCR_002798). Before performing any analysis, data were tested for normal distribution using the Shapiro-Wilk normality test and parametric or nonparametric tests were applied accordingly. For statistical analyses with two datasets, two-tailed paired $t$ test or Wilcoxon signed-rank test were used. For comparisons of more than two paired datasets, one-way repeatedmeasures ANOVA followed by Tukey's post hoc test or Friedman test followed by Conover's post hoc test or two-way repeated-measures ANOVA followed by Bonferroni's post hoc test were applied. For comparisons of more than two unpaired datasets, one-way ANOVA followed by Tukey's post hoc test or Kruskal-Wallis test followed by Dunn's post hoc test were used. In these cases, the $p$-value reported corresponds to the $p$-value of the post hoc test unless otherwise stated. Values of $p<0.05$ were considered significant. All data were expressed as mean \pm SEM unless otherwise stated.

Drugs and toxins. Stock solutions of DHPs (Nife \pm BayK-8644, Bay-K) were prepared in dimethyl sulfoxide (final concentration $\leq 0.1 \%$ ). Peptidic toxin stock solutions were prepared in distilled water. Reagents and IbTx were from Sigma-Aldrich, IbTx was also from Tocris Bioscience, and all other toxins and drugs were from Alomone Labs. All drugs and toxins were thawed and diluted in the extracellular solution just before use. In the case of peptidic toxins, the bath solution contained $0.01 \%$ bovine serum albumin.

\section{Results}

\section{Properties of the MOC-IHC synaptic transmission during} postnatal development

Synaptic strength increases from $\mathrm{P} 4$ to $\mathrm{P} 11$

From birth to hearing onset (P12), the MOC-IHC synapse undergoes dramatic changes in the sensitivity to ACh and in the expression of key postsynaptic proteins (Katz et al., 2004; Roux et al., 2011). To investigate whether these postsynaptic developmental changes were matched by presynaptic modifications, we first studied the strength of transmitter release at three postnatal stages, P4, P6-P7, and P9-P11.To this end, we evaluated the quantum content of electrically evoked ACh release and $P_{\text {success }}$ at these stages. Both parameters significantly increased from P4 to 
a

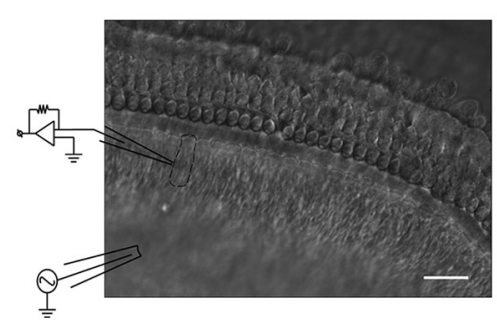

d

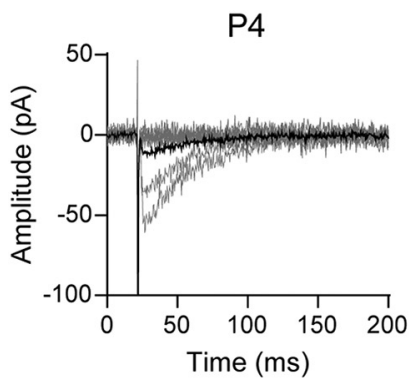

b

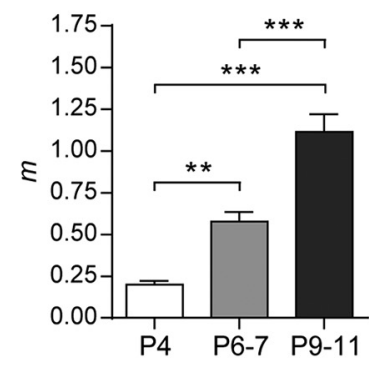

P6-7

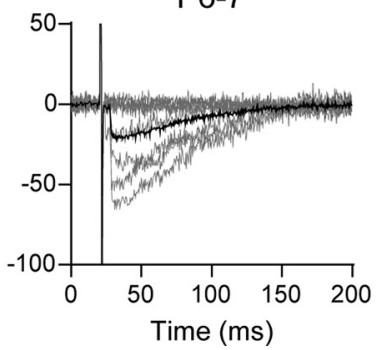

C

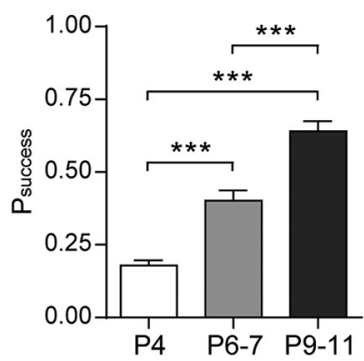

P9-11

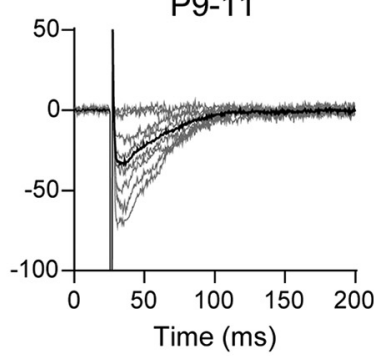

Figure 1. Synaptic strength at the mouse MOC-IHC synapse increases during postnatal development. $\boldsymbol{a}$, Micrograph of the mouse cochlear preparation used in the present study. IHCs were recorded with a patch pipette at a holding potential of $-90 \mathrm{mV}$ and MOC fibers were electrically stimulated using a monopolar electrode placed $\sim 80 \mu \mathrm{m}$ modiolar to the base of the IHCs. Scale bar, $20 \mu \mathrm{m} . \boldsymbol{b}$, Bar graph showing the progressive increase in $m$ from P4 to P9-P11. c, Bar graph illustrating the increase in $P_{\text {success }}$ during the same period shown in $\boldsymbol{b}$. $\boldsymbol{d}$, Representative individual (gray) and average (black) traces of elPSCs recorded at P4, P6-P7, and P9-P11 IHCs. Average elPSC amplitudes include failures of release. (See Materials and Methods for explanation of why we name these currents "inhibitory" although they are inward.) Data from P9-P11 are shown for comparison and were taken from Zorrilla de San Martín et al. (2010). Error bars indicate SEM. ${ }^{* *} p<0.01$, ${ }^{* * *} p<0.001$.

P11 (Fig. $1 b-d$ ). The quantum content evaluated by the direct method (see Materials and Methods) was as follows: $\mathrm{P} 4=0.20 \pm$ $0.02 ; \mathrm{P} 6-\mathrm{P} 7=0.58 \pm 0.06 ; \mathrm{P} 9-\mathrm{P} 11=1.12 \pm 0.11(\mathrm{P} 6-\mathrm{P} 7$ vs $\mathrm{P} 4$ $p=0.0036$; $\mathrm{P} 6-\mathrm{P} 7$ vs $\mathrm{P} 9-\mathrm{P} 11 p=7.40 \mathrm{e}^{-06} ; \mathrm{P} 4$ vs $\mathrm{P} 9-\mathrm{P} 11 p=$ $8.33 \mathrm{e}^{-04} ; n=17-24$ cells from $17-24$ mice). We also evaluated the decay kinetics of eIPSCs across the different stages and found no significant differences between them $(\mathrm{P} 4=41.02 \pm 2.74 \mathrm{~ms}$; $\mathrm{P} 6-\mathrm{P} 7=42.31 \pm 2.02 \mathrm{~ms} ; \mathrm{P} 9-\mathrm{P} 11=35.27 \pm 1.21 \mathrm{~ms} ; p=$ $0.0564 ; n=15-16$ IHC, 13-16 mice).

The quantum content values obtained by the failures method in the same cells (see Materials and Methods) were not significantly different to those obtained by the direct method: $\mathrm{P} 4=$ $0.20 \pm 0.02 ; \mathrm{P} 6-\mathrm{P} 7=0.54 \pm 0.06 ; \mathrm{P} 9-\mathrm{P} 11=1.16 \pm 0.11$. The probability of success was as follows: $\mathrm{P} 4=0.18 \pm 0.02$; $\mathrm{P} 6-\mathrm{P} 7=$ $0.40 \pm 0.04 ; \mathrm{P} 9-\mathrm{P} 11=0.64 \pm 0.04\left(\mathrm{P} 6-\mathrm{P} 7\right.$ vs $\mathrm{P} 4 p=3.22 \mathrm{e}^{-05}$; $\mathrm{P} 6-\mathrm{P} 7$ vs P9-P11 $p=2.20 \mathrm{e}^{-06}$; P4 vs P9-P11 $\left.p=1.20 \mathrm{e}^{-06}\right)$. This shows that synaptic transmission is significantly strengthened along this early postnatal developmental period.

We analyzed the amplitude and kinetics of the sIPSCs (Fig. 2). No significant changes either in sIPSC amplitude $(\mathrm{P} 4=21.16 \pm$ 1.47 pA; $66-\mathrm{P} 7=20.06 \pm 0.81 \mathrm{pA} ; \mathrm{P} 9-\mathrm{P} 11=20.62 \pm 1.34 \mathrm{pA}$; $p=0.9755 ; n=20$ cells, $18-19$ mice, $462-585$ events; Fig. $2 b, c)$ or kinetics (decay time constant $\mathrm{P} 4=30.90 \pm 1.62 \mathrm{~ms}, \mathrm{P} 6-\mathrm{P} 7=$ $34.50 \pm 2.39 \mathrm{~ms}, \mathrm{P} 9-\mathrm{P} 11=31.58 \pm 1.95 \mathrm{~ms}$; same cells and events as those used for amplitude measurements; $p=0.41$; Fig. $2 b-d$ ) were observed between the different stages. The fact that no changes were observed in sIPSC amplitudes indicates that the quantum size remains constant across the different ages studied. This suggests there are no changes either in the number of ACh molecules in each synaptic vesicle or in the postsynaptic sensitivity to ACh. Although less likely, we cannot preclude that changes in both of them might offset each other. Further, in agreement with previous work (Katz et al., 2004), the lack of changes in
sIPSC decay kinetics strongly suggest that the contribution of SK2 channels to the postsynaptic cholinergic response remains unchanged during the developmental period under study.

We also analyzed the frequency of occurrence of sIPSCs and found that, at $\mathrm{P} 4$, of 4 cells observed during 5-15 min, 3 were completely silent and only 1 had a sIPSC frequency of $0.01 \mathrm{~Hz}$. At P6-P7, the sIPSC frequency was $0.02 \pm 0.01 \mathrm{~Hz}(n=17$ cells, 17 mice) and it significantly increased at P9-P11: $0.18 \pm 0.07(n=$ 10 cells, 8 mice, $p=0.0095$, data not shown). The increase in the frequency of spontaneous events from P4 to P9-P11 was much higher than the increment observed in the quantum content of evoked release during the same period. This differential increment might possibly be due to the fact that both types of release are not only mechanistically different but have also a different dependence on $\mathrm{Ca}^{2+}$ (Kaeser and Regehr, 2014; Chanaday and Kavalali, 2018). Nevertheless, the significant increment in both types of release without changes in the amplitude of sIPSCs is consistent with a strengthening of the presynaptic release mechanisms during development.

\section{Developmental changes in STP}

Synapses are endowed with an extraordinary capacity to change according to their previous history. This gives rise to several forms of activity-dependent synaptic plasticity that shape synaptic output (Zucker and Regehr, 2002). Synapses with a high initial probability of release tend to depress, whereas those with a low initial probability of release tend to facilitate when challenged by closely spaced stimuli (Fioravante and Regehr, 2011). Facilitation upon high-frequency stimulation has been observed for efferent synapses on turtle auditory cells (Art et al., 1984), neonatal rat MOC-IHC synapses (Goutman et al., 2005), and also in mouse MOC-OHC synapses at the onset of hearing (Ballestero et al., 2011). In view of the significant differences in synaptic strength 
a

P4

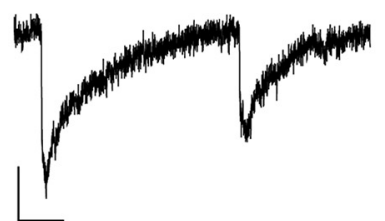

b

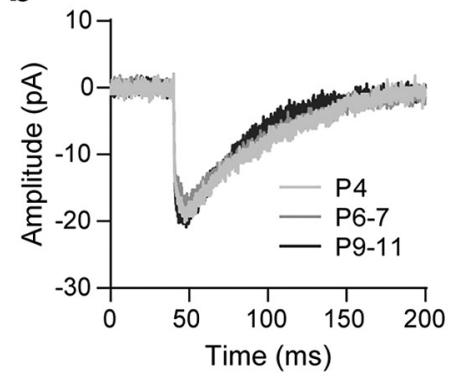

P6-7
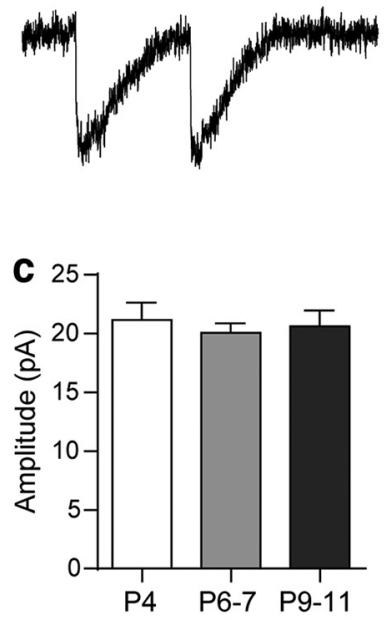

P9-11
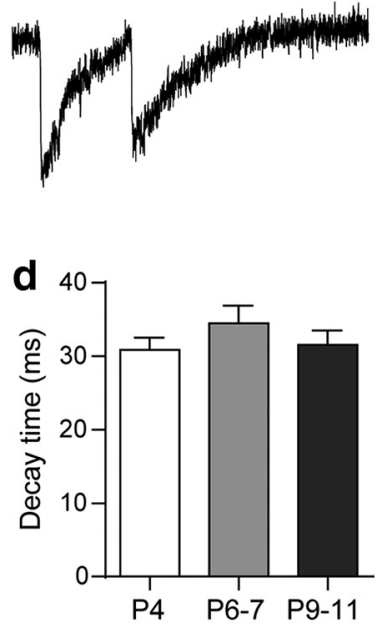

Figure 2. Biophysical properties of sIPSCs at the MOC-IHC synapse during postnatal development. $\boldsymbol{a}$, Representative traces of sIPSCs recorded at P4, P6 - P7, and P9-P11 IHCS (holding potential: $-90 \mathrm{mV})$. Vertical scale bar, $10 \mathrm{pA}$; horizontal scale bar, $50 \mathrm{~ms} . \boldsymbol{b}$, Representative average traces of sIPSCs recorded in one IHC from each developmental stage $(s \mathrm{IPSCs}, n:$ P4 $=23, \mathrm{P} 6-\mathrm{P7}=18$, P9-P11 = 27). $\boldsymbol{c}, \boldsymbol{d}$, Bar graphs illustrating that neither the sIPSC amplitude $(\boldsymbol{c})$ nor the decay time constant $(\boldsymbol{d})$ is modified during MOC-IHC synapse maturation. Error bars indicate SEM.

$10 \mathrm{~Hz}$
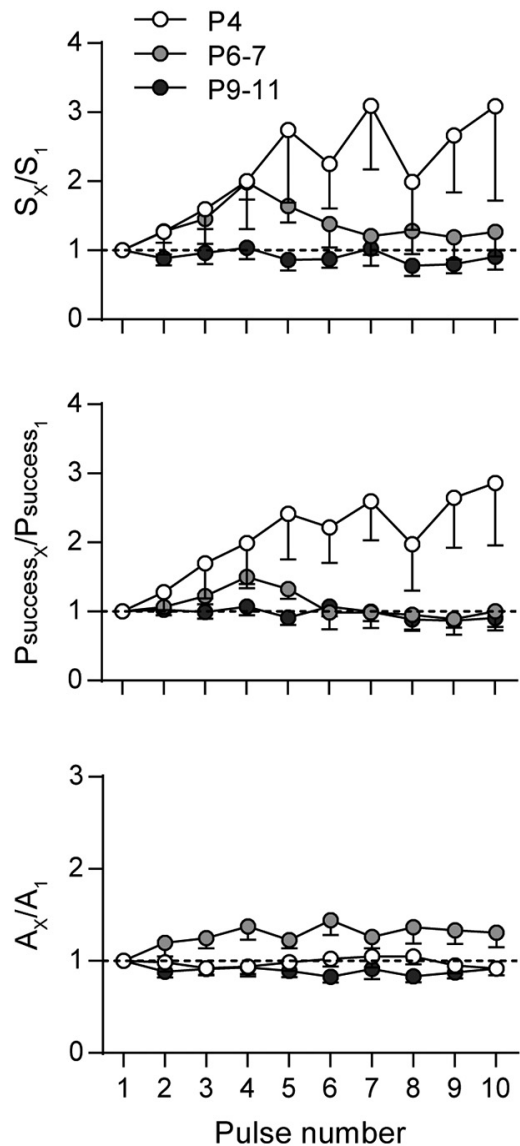

$40 \mathrm{~Hz}$
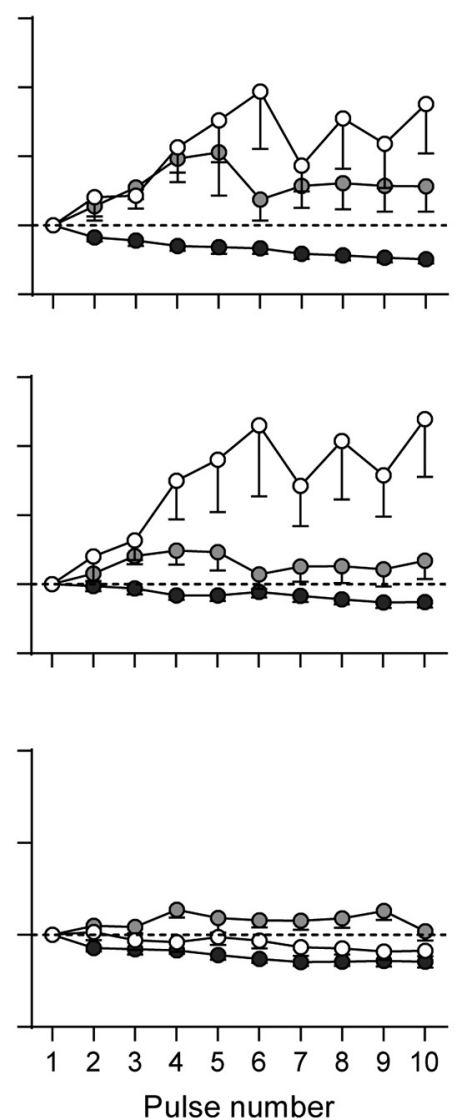

$100 \mathrm{~Hz}$
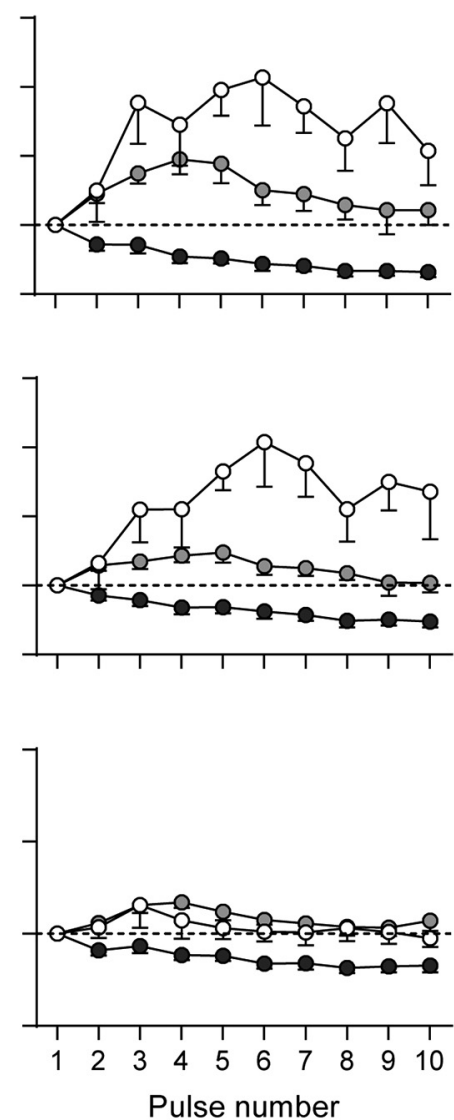

Figure 3. STP pattern at the MOC-IHC synapse changes from facilitation to depression during development. The normalized overall response $\left(S_{x} / S_{1}\right.$, top), probability of successfully evoking a release event $\left(P_{\text {success }} / P_{\text {success } 1}\right.$, middle), and average amplitude of successful responses $\left(A_{x} / A_{1}\right.$, bottom) are plotted against pulse number during 10 -pulse stimulation trains at 10,40 , and $100 \mathrm{~Hz}$. Experiments were done in IHCs at P4 (white circles), P6-P7 (light gray circles), and P9-P11 (dark gray circles). Error bars indicate SEM. 
Table 1. STP parameters of the MOC-IHC synapse at different stages of development

\begin{tabular}{|c|c|c|c|c|c|c|c|}
\hline Frequency & Age & Parameter & $X_{1}($ mean $\pm S E M)$ & $X_{\max (\min )}($ mean \pm SEM $)$ & $p$ & Stimulus no. & $\bar{n}$ \\
\hline \multirow[t]{9}{*}{$10 \mathrm{~Hz}$} & \multirow[t]{3}{*}{ P4 } & $S$ & $1.55 \pm 0.43$ & $4.79 \pm 1.07$ & $9.9 e^{-06}$ & \multirow[t]{3}{*}{7} & \multirow[t]{3}{*}{13} \\
\hline & & $P_{\text {success }}$ & $0.07 \pm 0.02$ & $0.19 \pm 0.03$ & $2.3 e^{-05}$ & & \\
\hline & & $A$ & $21.88 \pm 2.17$ & $21.58 \pm 3.27$ & 0.9965 & & \\
\hline & \multirow[t]{3}{*}{ P6-P7 } & $S$ & $8.31 \pm 1.05$ & $16.44 \pm 2.47$ & $3.6 \mathrm{e}^{-05}$ & \multirow[t]{3}{*}{4} & \multirow[t]{3}{*}{12} \\
\hline & & $P_{\text {success }}$ & $0.43 \pm 0.05$ & $0.61 \pm 0.06$ & 0.0022 & & \\
\hline & & $A$ & $19.52 \pm 0.84$ & $26.24 \pm 2.37$ & 0.289 & & \\
\hline & \multirow[t]{3}{*}{ P9-P11 } & $S$ & $24.18 \pm 3.23$ & $16.09 \pm 2.86$ & $7.6 e^{-08}$ & \multirow[t]{3}{*}{8} & \multirow[t]{3}{*}{20} \\
\hline & & $P_{\text {success }}$ & $0.72 \pm 0.06$ & $0.55 \pm 0.07$ & $2.6 \mathrm{e}^{-06}$ & & \\
\hline & & $A$ & $31.50 \pm 2.25$ & $25.32 \pm 2.17$ & 0.7289 & & \\
\hline \multirow[t]{9}{*}{$40 \mathrm{~Hz}$} & \multirow{3}{*}{ P4 } & $S$ & $2.92 \pm 0.79$ & $6.48 \pm 1.91$ & 0.00019 & \multirow[t]{3}{*}{6} & \multirow[t]{3}{*}{11} \\
\hline & & $P_{\text {success }}$ & $0.13 \pm 0.04$ & $0.31 \pm 0.07$ & 0.00010 & & \\
\hline & & $A$ & $22.57 \pm 2.53$ & $19.48 \pm 2.38$ & 0.6703 & & \\
\hline & \multirow[t]{3}{*}{ P6-P7 } & $s$ & $10.68 \pm 1.35$ & $19.20 \pm 3.12$ & 0.0055 & \multirow[t]{3}{*}{4} & \multirow[t]{3}{*}{11} \\
\hline & & $P_{\text {success }}$ & $0.44 \pm 0.04$ & $0.64 \pm 0.08$ & $3.6 e^{-05}$ & & \\
\hline & & $A$ & $23.45 \pm 1.40$ & $28.98 \pm 1.71$ & 0.4565 & & \\
\hline & \multirow[t]{3}{*}{ P9-P11 } & S & $28.61 \pm 4.59$ & $12.83 \pm 1.66$ & $5.0 e^{-14}$ & \multirow[t]{3}{*}{10} & \multirow[t]{3}{*}{13} \\
\hline & & $P_{\text {success }}$ & $0.77 \pm 0.05$ & $0.57 \pm 0.07$ & $6.2 e^{-08}$ & & \\
\hline & & $A$ & $34.82 \pm 3.08$ & $22.34 \pm 1.36$ & 0.0828 & & \\
\hline \multirow{9}{*}{$100 \mathrm{~Hz}$} & \multirow{3}{*}{ P4 } & $s$ & $1.04 \pm 0.21$ & $3.49 \pm 0.98$ & 0.0054 & \multirow[t]{3}{*}{6} & 11 \\
\hline & & $P_{\text {success }}$ & $0.08 \pm 0.01$ & $0.23 \pm 0.04$ & 0.0004 & & \\
\hline & & A & $12.65 \pm 1.31$ & $13.51 \pm 1.43$ & 0.3767 & & \\
\hline & \multirow[t]{3}{*}{ P6-P7 } & $S$ & $12.59 \pm 1.71$ & $22.95 \pm 2.39$ & $3.8 \mathrm{e}^{-06}$ & \multirow[t]{3}{*}{4} & 8 \\
\hline & & $P_{\text {success }}$ & $0.53 \pm 0.05$ & $0.74 \pm 0.05$ & $8.0 e^{-06}$ & & \\
\hline & & $A$ & $23.15 \pm 1.05$ & $30.77 \pm 1.20$ & 0.0014 & & \\
\hline & \multirow[t]{3}{*}{ P9-P11 } & $S$ & $29.28 \pm 4.01$ & $8.23 \pm 1.52$ & $1.17 \mathrm{e}^{-10}$ & \multirow[t]{3}{*}{10} & 13 \\
\hline & & $P_{\text {success }}$ & $0.81 \pm 0.05$ & $0.37 \pm 0.06$ & $5.6 e^{-15}$ & & \\
\hline & & $A$ & $34.78 \pm 2.71$ & $21.74 \pm 1.40$ & 0.0012 & & \\
\hline
\end{tabular}

Stimulation trains consisting of 10 pulses at 10,40 , and $100 \mathrm{~Hz}$ were applied at $\mathrm{P} 4, \mathrm{P} 6-\mathrm{P} 7$, and $\mathrm{P9}-\mathrm{P} 11 \mathrm{IH}\left(\mathrm{s}\right.$. S, $P_{\text {success }}$ and $A$ were computed for each pulse. The first pulse values $\left(X_{1}\right)$ and the maximum (in case of facilitation) or minimum value (in case of depression) $\left(X_{\max (\min )}\right)$ for $S, P_{\text {success }}$ and $A$ are shown for each dataset. The $p$-values correspond to one-way ANOVA/Friedman test results when no significant differences were found; otherwise, they correspond to the multiple-comparisons post hoc test result for $X_{\max (\min )}$ shown. S and $A$ values are in $\mathrm{pA}$. At all ages, the reported number of cells was obtained from 7-13 mice.

observed at the MOC-IHC synapse between P4, P6-P7, and P9$\mathrm{P} 11$, we investigated whether these differences were reflected in their STP pattern by studying the behavior of the MOC-IHC synapse upon application of high-frequency stimulation trains. We analyzed $S, P_{\text {success }}$, and $A$ along high-frequency (10, 40, and $100 \mathrm{~Hz}$ ) stimulation 10-pulse trains. The normalized values along the train are shown in Figure 3 ( $S$ at the top, $P_{\text {success }}$ in the middle, and $A$ at the bottom). Normalized values $>1$ indicate facilitation, whereas values $<1$ indicate depression (Katz and Miledi, 1968; Goutman et al., 2005, Ballestero et al., 2011). Synapses from P4 mice facilitated at the three frequencies tested and along the whole 10-pulse protocols. At all frequencies, the increase in $S$ is accounted for by a reduction in the number of failures and a concomitant increase in $P_{\text {success }}$, with no significant changes in $A$ (Fig. 3, Table 1). Synapses from P6-P7 mice presented significant facilitation at the three frequencies tested, reaching a maximum at the fourth pulse of the 10-pulse protocol and then fading away (Fig. 3, Table 1). This suggests that, during the train, the mechanisms leading to depression balance those leading to facilitation. At this stage, the increase in $S$ is also accounted for by an increase in $P_{\text {success }}$ and, at $100 \mathrm{~Hz}$, there was also a slight but significant increment in $A$. This increment in $A$ suggests that there might be an increase in the average number of vesicles released during the first part of the $100 \mathrm{~Hz}$ train. At P9-P11, there was a significant reduction in $S$ and $P_{\text {success }}$ at 10, 40, and $100 \mathrm{~Hz}$, being more pronounced at $100 \mathrm{~Hz}$ toward the end of the stimulation train (Fig. 3, Table 1). A significant reduction in $A$ was also found at $100 \mathrm{~Hz}$, suggesting either a reduction in the average number of vesicles released along the high-frequency stimulation train or a postsynaptic effect due to saturation or desensitization of the postsynaptic receptors (Scheuss et al., 2002; Taschenberger et al., 2005). However, receptor saturation and/or desensitization of the IHC $\alpha 9 \alpha 10$ nAChR under these conditions are not likely because the exogenous application of $1 \mathrm{~mm}$ ACh to cochlear IHCs can evoke currents $>0.5 \mathrm{nA}$ with desensitization time constants significantly longer than the duration of the stimulation trains used in the present work $(\tau$ decay $=13.8 \pm 0.5 \mathrm{~s}$ and $\tau$ decay $=$ $37.9 \pm 4.2 \mathrm{~s}$ for the continuous and intermittent application of ACh, respectively (Gómez-Casati et al., 2005).

STP is sensitive to changes in the initial probability of release Most synapses possess multiple forms of plasticity and the net synaptic strength depends on the interaction between them. Short-term depression and facilitation are both present at a given synapse, but the relative prominence of each one is controlled by the initial probability of release (Regehr, 2012). Because the probability of release is highly sensitive to the external $\mathrm{Ca}^{2+}$ concentration (Dodge and Rahamimoff, 1967), we evaluated whether changing this parameter by manipulating $\left[\mathrm{Ca}^{2+}\right]_{\mathrm{o}}$ affected the STP pattern at P6-P7 and P9-P11. At P6-P7, increasing $\left[\mathrm{Ca}^{2+}\right]_{0}$ from 1.3 to $1.5 \mathrm{~mm}$ caused a significant increase in the quantum content of evoked release $\left(\mathrm{Ca}^{2+} 1.3 \mathrm{~mm}, m=0.36 \pm 0.06\right.$, $\mathrm{Ca}^{2+} 1.5 \mathrm{~mm}, m=0.69 \pm 0.14, n=10$ cells, 6 mice, $p=0.0180$; Fig. 4a). Under this condition, applying a $100 \mathrm{~Hz} 10$ pulse train, the STP pattern changed from facilitation to depression $\left(\mathrm{Ca}^{2+}\right.$ $1.3 \mathrm{~mm}, n=15$ cells, 12 mice, $\mathrm{Ca}^{2+} 1.5 \mathrm{~mm}, n=9$ cells, 6 mice; Fig. 4b). Using the same rationale, at P9-P11, we reduced $\left[\mathrm{Ca}^{2+}\right]_{\mathrm{o}}$ from 1.3 to $1.1 \mathrm{~mm}$. This caused a significant reduction in the quantum content of evoked release $\left(\mathrm{Ca}^{2+} 1.3 \mathrm{~mm}, m=\right.$ $1.43 \pm 0.36, \mathrm{Ca}^{2+} 1.1 \mathrm{mM}, m=0.89 \pm 0.25, n=7$ cells, 5 mice, $p=0.0304$; Fig. $4 c$ ) and a concomitant change in the STP pattern that changed from depression to facilitation $\left(\mathrm{Ca}^{2+} 1.3 \mathrm{mM}, n=\right.$ 16 cells, 12 mice, $\mathrm{Ca}^{2+} 1.1 \mathrm{~mm}, n=10$ cells, 6 mice; Fig. $4 d$ ). 
Both the size of the readily releasable pool of vesicles and its replenishment rate increase during development

The increase in $m$ observed during development can be due to changes either in the probability of release or in the available number of synaptic vesicles (RRP). As reported above, there was both an increase in the probability of successfully evoking a release event (Fig. 1) and a significant increment in the probability of appearance of spontaneous events across the three developmental stages studied. To test whether there were also changes in the RRP size at the MOC synaptic terminals contacting the IHCs during postnatal development, we applied high-frequency stimulation trains (50 pulses at $100 \mathrm{~Hz}$; 10-30 times) at each of the developmental stages studied (P4, P6-P7, and P9-P11). Representative examples of these trains are illustrated in Figure 5, $a-c$. The cumulative mean amplitude along the train was calculated for each of the stimulation pulses and the last 20 points of the plot were fitted with a linear function. Representative cumulative amplitude plots are shown in Figure 5, $d-f$. The intercept of the linear fit divided by the quantum size (mean amplitudes of sIPSCs at each stage; Fig. $2 c$ ) is the RRP size and the slope of this linear regression is the rate at which the synapse replenishes the docking sites with new synaptic vesicles (Schneggenburger et al., 1999; Neher, 2015). There was a significant increase in the size of the RRP between $\mathrm{P} 4$ and $\mathrm{P} 9-\mathrm{P} 11: \mathrm{P} 4=1.04 \pm 0.28$ vesicles; at $\mathrm{P} 6-\mathrm{P} 7=$ $3.82 \pm 0.81$ vesicles and at $\mathrm{P} 9-\mathrm{P} 11=6.46 \pm 1.12$ vesicles $(n=$ $12-15$ cells from $7-10$ mice). Significant differences were observed when comparing P4 versus P6-P7 $(p=0.0093)$ and $\mathrm{P} 4$ versus P9-P11 $\left(p=2.5 \mathrm{e}^{-05}\right)$, but not $\mathrm{P} 6-\mathrm{P} 7$ versus $\mathrm{P} 9-\mathrm{P} 11$ $(p=0.1023$; Fig. $5 g, h)$. A significant increase of the replenishment rate between $\mathrm{P} 4$ and $\mathrm{P} 11$ was also observed. Replenishment rate at $\mathrm{P} 4: 5.71 \pm 1.39$ vesicles/s, at $\mathrm{P} 6-\mathrm{P} 7: 13.48 \pm 2.81$ vesicles/s and at P9-P11: $22.95 \pm 3.33$ vesicles/s. Significant differences were observed when comparing P4 versus P6-P7 ( $p=0.034), \mathrm{P} 4$ versus $\mathrm{P} 9-\mathrm{P} 11\left(p=2.4 \mathrm{e}^{-05}\right)$, and $\mathrm{P} 6-\mathrm{P} 7$ versus $\mathrm{P} 9-\mathrm{P} 11(p=$ 0.032; Fig. 5i).

Even though we assume that each current pulse generates only one action potential, we cannot completely disregard the possibility of asynchronous spikes being generated due to resonance in the neuron. This could introduce some bias in the estimations of RRP size and replenishment rate. Notwithstanding, this possibility seems unlikely for the following reasons: (1) the duration of stimulation pulses used $(<200 \mu \mathrm{s})$ is enough to reliably evoke action potentials but still shorter than the duration of a typical central nervous system action potential (1-2 ms), so it is doubtful that it would trigger more than one action potential or resonant oscillations of the axon membrane potential; and (2) at the three developmental stages studied, cumulative amplitude plots show a clear transition after $\sim 10$ pulses to a linear regime that corresponds to the release of exclusively newly recruited vesicles show-
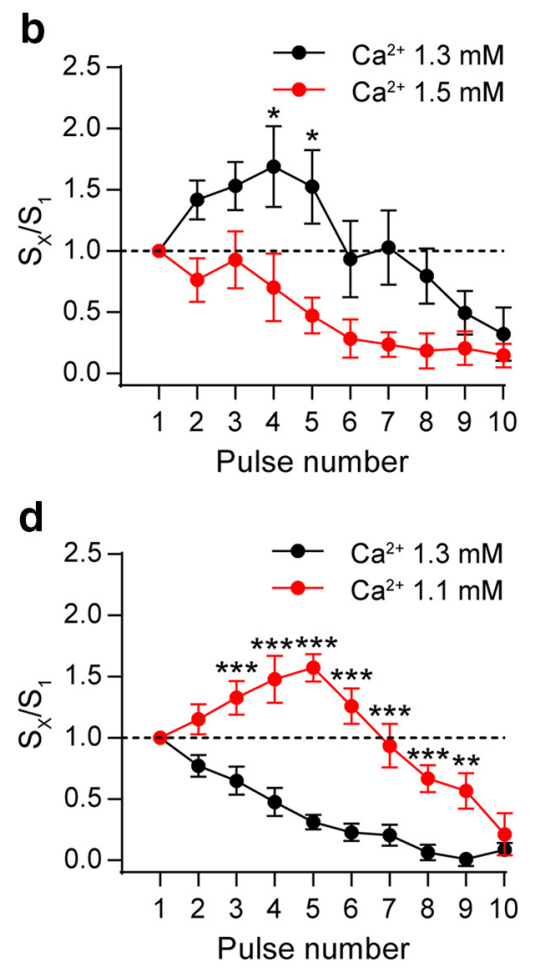

Figure 4. Changes in the initial probability of release modify the STP pattern. $\boldsymbol{a}$, Graph showing that, in P6 - P7 IHCs, an increase in $\left[\mathrm{Ca}^{2+}\right]$ from 1.3 (black circles) to $1.5 \mathrm{~mm}$ (orange circles) significantly increased $m$. The mean $\pm S E M$ values of $m$ measured in the decrease in $m$ at P9-P11 IHCs after changing [ $\left[\mathrm{Ca}^{2+}\right]_{0}$ from 1.3 to $1.1 \mathrm{~mm}$. d, Normalized amplitude of elPSCs $\left(S_{x} / S_{1}\right)$ plotted against pulse number during 10-pulse stimulations trains at $100 \mathrm{~Hz}$ recorded in both $\left[\mathrm{Ca}^{2+}\right]_{0}$ conditions in P9-P11 IHCs. In this case, the STP pattern changed from depression at $\left[\mathrm{Ca}^{2+}\right]_{0}=1.3 \mathrm{~mm}$ to facilitation at $\left[\mathrm{Ca}^{2+}\right]_{0}=1.1 \mathrm{~mm}$. Error bars indicate SEM. ${ }^{*} p<0.05,{ }^{* *} p<0.01,{ }^{* * *} p<0.001$.

ing that the RRP can be efficiently depleted with the stimulation protocols used.

From these experimental data, we estimated the $P_{\text {vesicle }}$ (Schneggenburger et al., 1999; Valera et al., 2012). By calculating the ratio between the average number of vesicles released per action potential (quantum content) and the number of vesicles ready to be released (RRP size), $P_{\text {vesicle }}$ was obtained for each cell in which the RRP size was determined. No significant differences were observed in this parameter across the three stages studied (P4: $P_{\text {vesicle }}=0.16 \pm 0.05 ; \mathrm{P} 6-\mathrm{P} 7: P_{\text {vesicle }}=0.18 \pm 0.03 ; \mathrm{P} 9-\mathrm{P} 11$ : $P_{\text {vesicle }}=0.19 \pm 0.03 ; p=0.825$; Fig. $5 j ; n=9-12$ cells from $7-8$ mice). Together, these results suggest that the increase in the RRP size and replenishment rate account for the increment in synaptic strength observed during development.

Ion channels coupled to the release process at the transient MOC-IHC synapse during postnatal development

Developmental changes in $\mathrm{Ca}^{2+}$ channels coupled to ACh release $\mathrm{Ca}^{2+}$ channels coupled to transmitter release have been shown to be developmentally regulated both at central synapses (Iwasaki et al., 2000; Momiyama, 2003; Fedchyshyn and Wang, 2005) and at the NMJ (Rosato Siri and Uchitel, 1999). In a previous study using electrophysiological and pharmacological methods, we showed that transmitter release at the transient MOC-IHC synapse at P9-P11 is supported by P/Q- and N-type VGCCs (Zorrilla de San Martín et al., 2010). In view of the significant presynaptic functional changes found in synaptic strength and STP pattern between the different ages studied, we investigated 
a

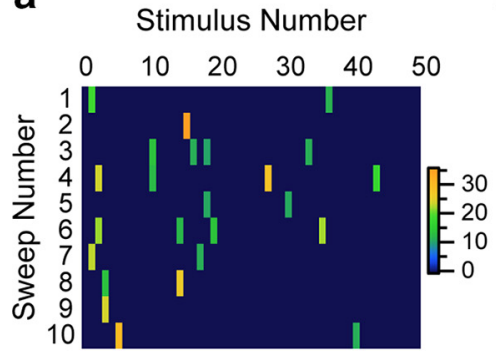

b

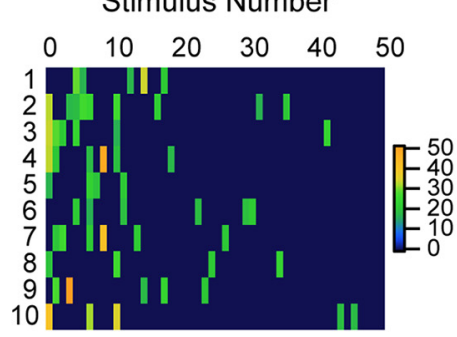

c

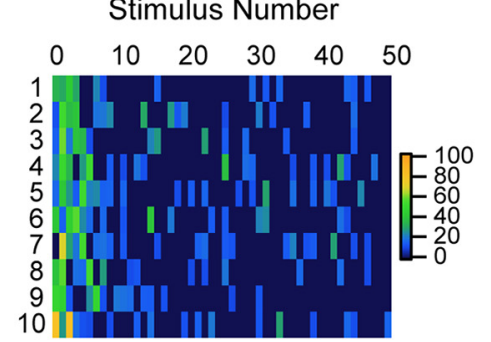

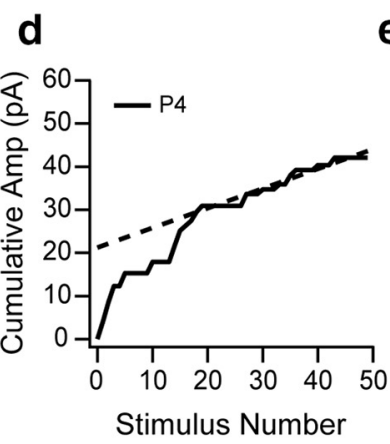

h

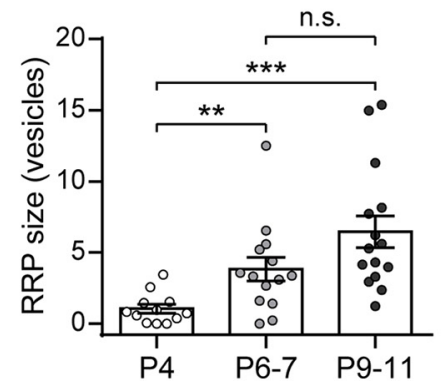

e

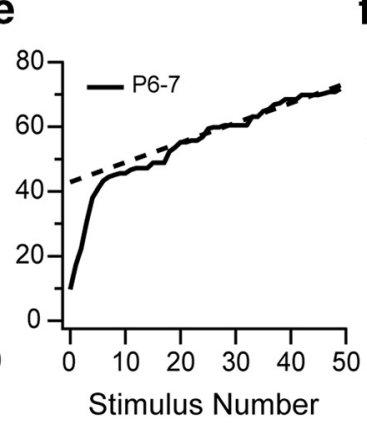

f

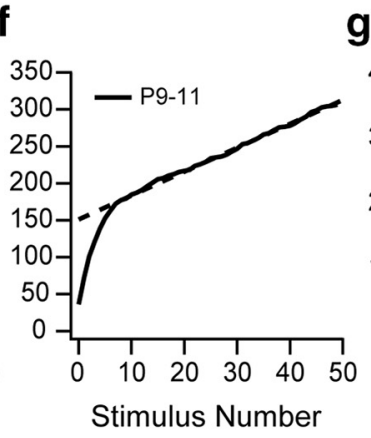

g

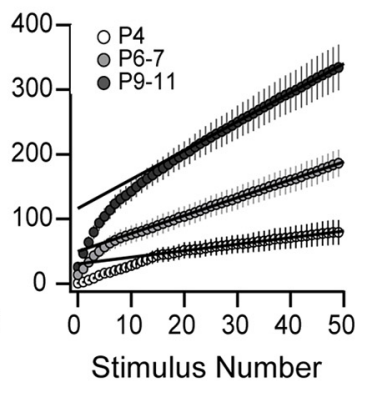

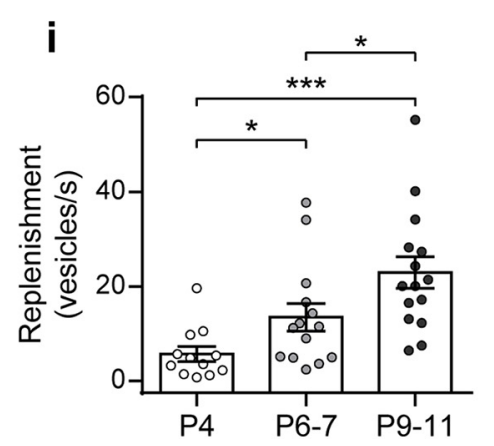

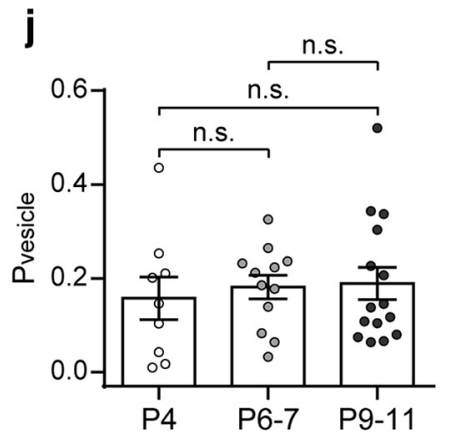

Figure 5. Size of the RRP and its replenishment rate increase during development. $\boldsymbol{a}-\boldsymbol{c}$, Color coded rectangles represent the amplitudes of the elPSCs evoked by trains ( 50 pulses at $100 \mathrm{~Hz}$, each panel shows 10 sweeps/columns) applied to P4, P6-P7, and P9-P11 IHCs. Color scale bars are expressed in pA. $\boldsymbol{d}$ - $\boldsymbol{f}$, Representative examples of the average cumulative amplitude plots built to estimate the RRP and replenishment rate (continuous lines are the cumulative amplitudes and the dashed lines are the linear fits of the last 20 points of the plot). $g$, Cumulative plots built with the pooled data show the increase of the intercept at each of the developmental stages (P4: white; P6 - P7: light gray; P9 -P11: dark gray). $\boldsymbol{h}$, Summary plot showing the increase in RRP size during development. $\boldsymbol{i}$, Summary plot showing the increase in synaptic vesicles replenishment rate during high-frequency stimulation at the same time period. $\boldsymbol{j}$, Summary plot illustrating that $P_{\text {vesicle }}$ remains constant throughout the developmental stages analyzed. Error bars indicate SEM. ${ }^{*} p<0.05,{ }^{* *} p<0.01,{ }^{* * *} p<0.001$.

whether the VGCC coupled to the release process at the transient MOC-IHC synapse were also developmentally regulated. We evaluated the quantum content of transmitter release at P4, P6$\mathrm{P} 7$, and $\mathrm{P} 9-\mathrm{P} 11$ in the presence of toxins that specifically antagonize P/Q-, N-, and R-type VGCCs (Mintz and Bean, 1993; Olivera et al., 1994; Newcomb et al., 1998; Bourinet et al., 2001). $\omega$-Aga (200 nm), $\omega$-CgTx GVIA (500 nm), and SNX (500 nм) were used to block P/Q-, N-, and R-type VGCCs, respectively. The effects of these $\mathrm{Ca}^{2+}$ channel blockers on evoked release at the three postnatal stages studied are illustrated in Figure 6. At P4 and P6-P7, both $\omega$-Aga and SNX significantly reduced the quantum content of evoked release $\left(\mathrm{P} 4: m_{\text {control }}=0.27 \pm 0.05, m_{\omega \text {-Aga }}=\right.$ $0.08 \pm 0.03, p=0.0029 ; m_{\text {control }}=0.26 \pm 0.07, m_{\mathrm{SNX}}=0.10 \pm$ $0.03, p=0.0295$. P6-P7: $m_{\text {control }}=0.44 \pm 0.07, m_{\omega \text {-Aga }}=0.17 \pm$ $0.04, p=0.0035 ; m_{\text {control }}=1.22 \pm 0.32, m_{\mathrm{SNX}}=0.50 \pm 0.13, p=$ $0.0294 ; n=5$ cells from 5 mice). The N-type VGCC blocker $\omega$-CgTx, however, had no significant effect on evoked release at these two stages $\left(\mathrm{P} 4: m_{\text {control }}=0.46 \pm 0.25, m_{\omega \text {-CgTx }}=0.40 \pm\right.$ $0.13, p=0.6557$. P6-P7: $m_{\text {control }}=0.46 \pm 0.09, m_{\omega-\operatorname{CgTx}}=$ $0.44 \pm 0.05, p=0.597 ; n=3-5$ cells from $3-5$ mice). As previ- ously reported, at P9-P11 (Zorrilla de San Martín et al., 2010), both the P/Q- and the N-type channel blockers significantly reduced evoked release (note: data for these two toxins at this stage were taken from those used in Zorrilla de San Martín et al., 2010); they were tested for normal distribution, reanalyzed and illustrated for comparison). Therefore, $m_{\text {control }}=0.86 \pm 0.31, m_{\omega \text {-Aga }}$ $=0.30 \pm 0.07, p=0.0313 ; m_{\text {control }}=0.62 \pm 0.12, m_{\omega-\operatorname{CgTx}}=$ $0.35 \pm 0.16, p=0.014 ; n=5-6$ cells from $5-6$ mice). At P9-P11, the R-type VGCC blocker SNX did not have a significant effect on the quantum content of evoked release $\left(m_{\text {control }}=0.42 \pm 0.14\right.$, $m_{\mathrm{SNX}}=0.25 \pm 0.07, n=6$ cells, 6 mice, $\left.p=0.1563\right)$. Together, these results clearly show that there is a change in the VGCC subtypes coupled to the ACh release process during the critical period during which the MOC-IHC synapse is functional. At the earliest periods (P4 to 7), N-type VGCCs do not participate in evoked ACh release, which is supported by both $\mathrm{P} / \mathrm{Q}$ - and R-type VGCCs. At P9-P11, both P/Q- and N-type VGCC support release, whereas at this stage, R-type channels are not coupled to this process. 
a
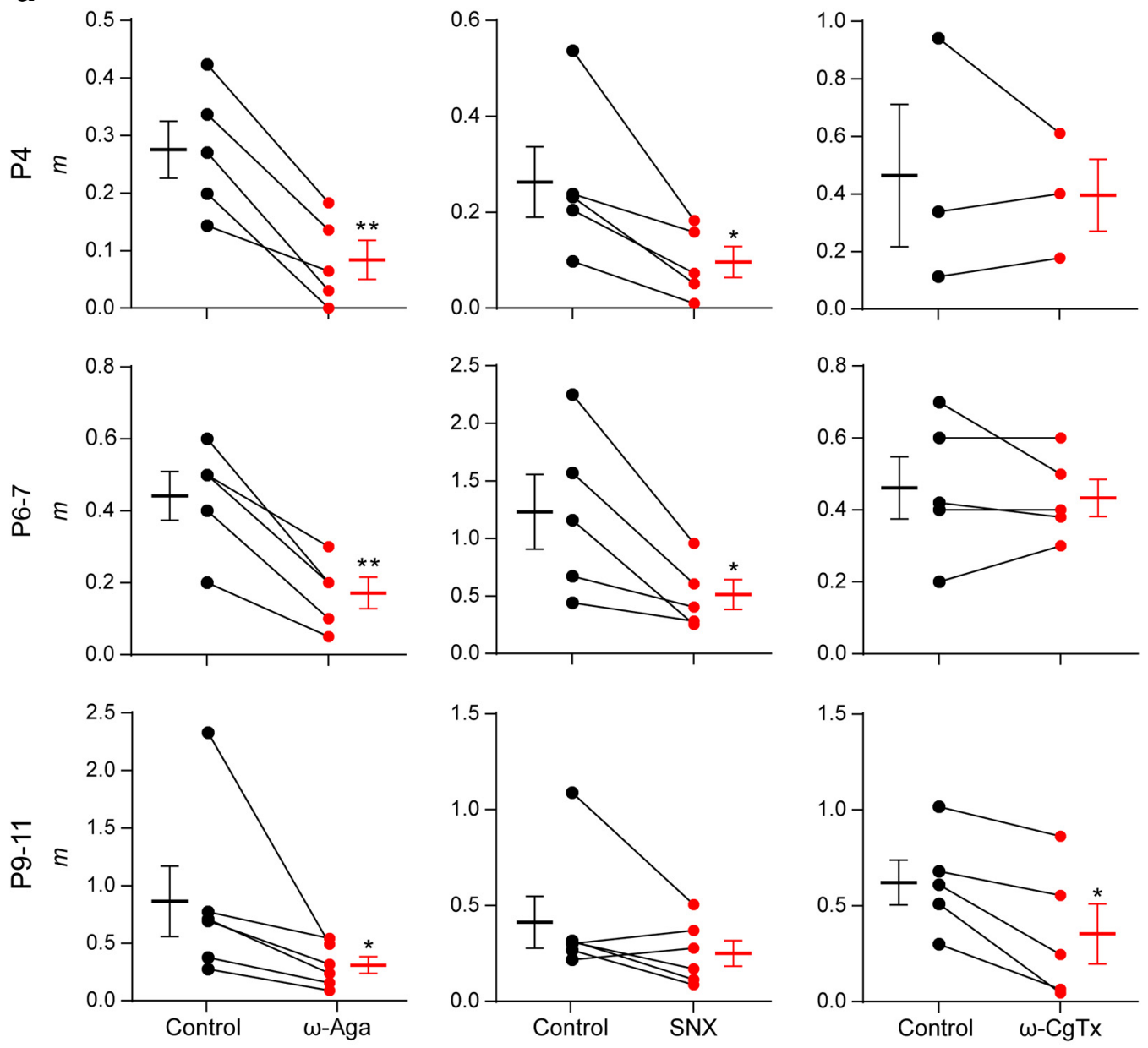

b

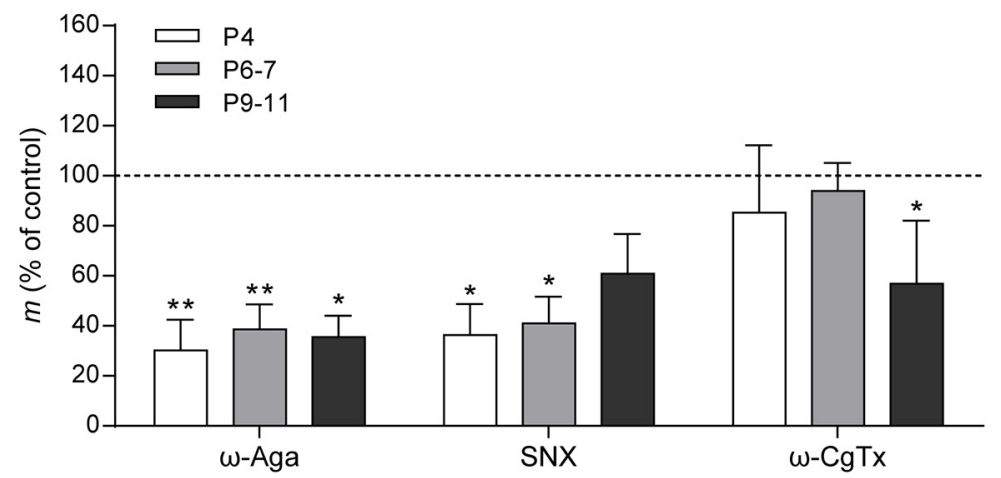

Figure 6. Different types of VGCCs support ACh release at the MOC-IHC synapse during postnatal development. $a$, Graph showing the effect on $m$ of $200 \mathrm{~nm} \omega$-Aga IVA, $500 \mathrm{~nm} \mathrm{SNX}$, and $500 \mathrm{~nm}$ $\omega$-CgTx, P/Q-, R-, and N-type VGCC-specific antagonists, respectively, in P4, P6-P7, and P9-P11 cochlear preparations (control: black circles, treated: red circles). The mean \pm SEM values of $m$ measured before and after toxin treatment are plotted to the left and right of their respective individual responses. $d$, Bar graph summarizing the effect on $m$ of $200 \mathrm{~nm} \omega$-Aga, $500 \mathrm{~nm}$ SNX, and 500 nм $\omega$-CgTx at the different stages of development. Note that R-type VGCCs contribute to the release process only during early stages of development (P4 and P6-P7), whereas N-type VGCCs begin to support ACh release at a later period (P9-P11) ( $\omega$-Aga $m$ percentage of control: $P 4=30.17 \pm 12.30, P 6-P 7=38.64 \pm 9.91, P 9-P 11=35.47 \pm 8.60 ;$ SNX $m$ percentage of control: $P 4=$ $36.32 \pm 12.47, \mathrm{P} 6-\mathrm{P} 7=41.04 \pm 10.68, \mathrm{P} 9-\mathrm{P} 11=60.88 \pm 15.89 ; \omega$-CgTx $m$ percentage of control: $\mathrm{P} 4=85.32 \pm 26.92 ; \mathrm{P} 6-\mathrm{P} 7=93.97 \pm 11.19 ; \mathrm{P} 9-\mathrm{P} 11=56.92 \pm 25.14) . \mathrm{Data}$ from P9-P11 mice are shown for comparison and were taken from Zorrilla de San Martín et al. (2010). Error bars indicate SEM. ${ }^{*} p<0.05,{ }^{* *} p<0.01$.

Role of L-type VGCC in the release process changes during development

L-type VGCCs do not support transmitter release at fast synapses under normal conditions (Catterall, 2011). However, they have been shown to participate in this process at reinnervating (Katz et al., 1996) and developing neuromuscular synapses (Sugiura and Ko, 1997; Rosato Siri and Uchitel, 1999). It has also been reported that motoneurons possess silent L-type channels that may be recruited to facilitate transmitter release during high-frequency bursts (Oliveira et al., 2004). In addition, L-type VGCCs are involved in the regulation of transmitter release at several synapses by the activation of $\mathrm{Ca}^{2+}$-dependent $\mathrm{K}^{+}$conductances (Marrion and Tavalin, 1998; Prakriya and Lingle, 1999; Sun et al., 2003; Loane et al., 2007; Marcantoni et al., 2007; Müller et al., 2007; 
a
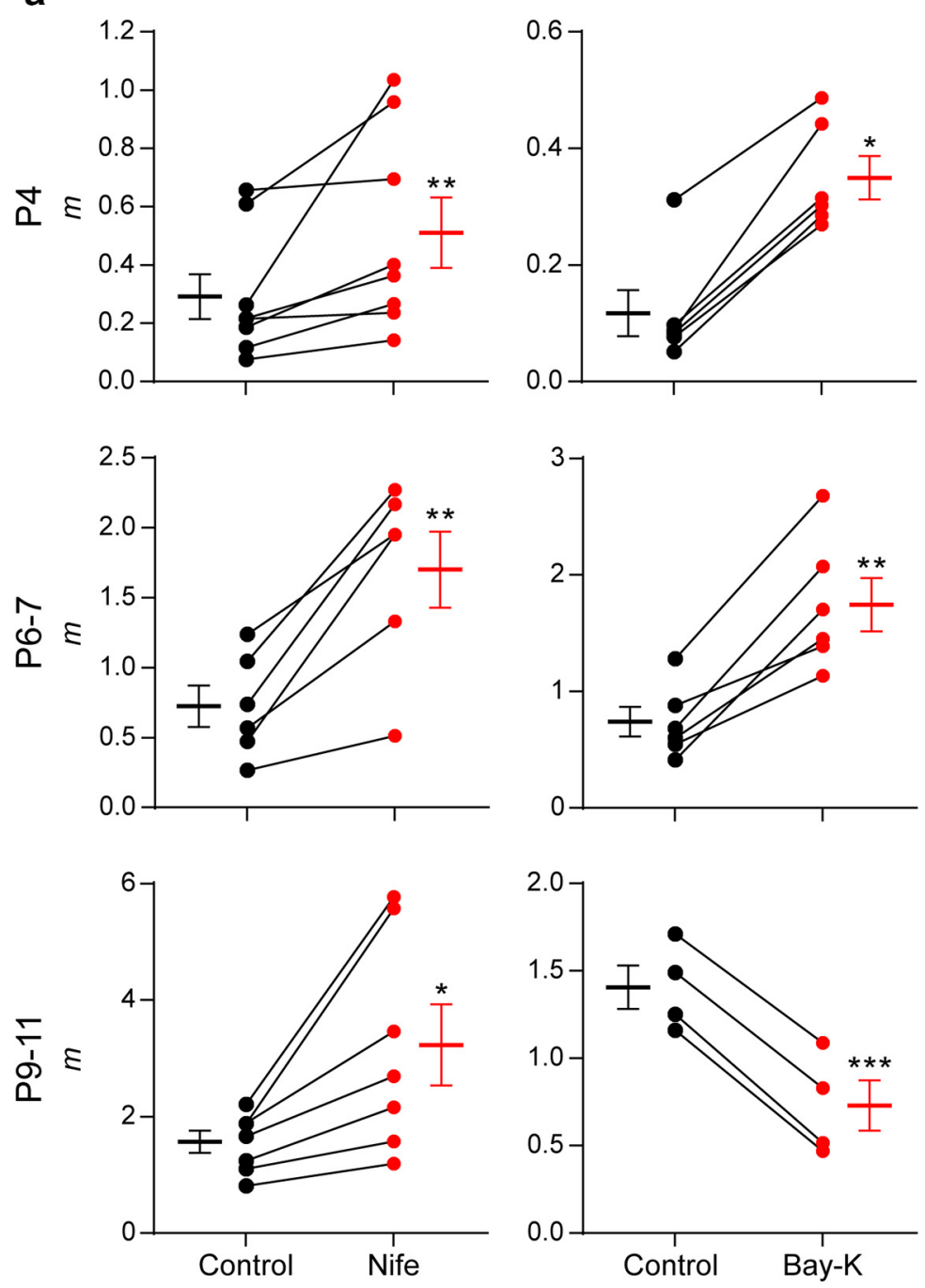

b

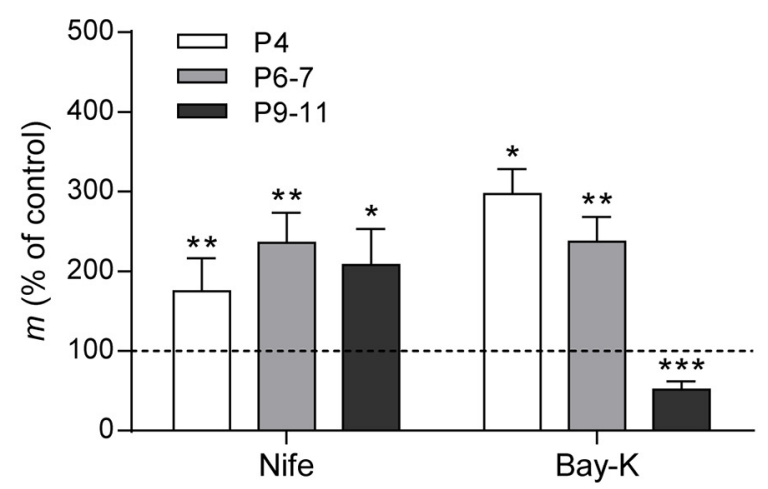

Figure 7. Role of L-type VGCC in transmitter release at the MOC-IHC synapse changes during development. $\boldsymbol{a}$, Graph showing the effect on $m$ of $3 \mu \mathrm{m}$ Nife and $10 \mu \mathrm{M}$ Bay-K 8644, an antagonist and an agonist of L-type VGCCs, respectively, in cochlear preparations from mice at P4, P6 $-\mathrm{P7}$, and P9-P11 (control: black circles, treated: red circles). The mean \pm SEM values of $m$ measured before and after toxin treatment are plotted to the left and right of their respective individual responses. $\boldsymbol{b}$, Bar graph summarizing the effect on $m$ of $3 \mu \mathrm{m}$ Nife and $10 \mu \mathrm{m}$ Bay-K at the different stages of development evaluated. At P4 and P6 -P7, both L-type VGCC antagonist and agonist increase $m$ (Nife $m$ percentage of control: P4 $=175.13 \pm 41.26 ; P 6-P 7=235.47 \pm$ $37.74 ; \mathrm{P} 9-\mathrm{P} 11=207.69 \pm 45.13 ;$ Bay-Km percentage of control:P4 = 297.02 $\pm 31.54 ; \mathrm{P} 6-\mathrm{P} 7=237.13 \pm 31.18 ; \mathrm{P} 9-\mathrm{P} 11=$ $51.74 \pm 10.33)$. Data from P9-P11 mice are shown for comparison and were taken from Zorrilla de San Martín et al. (2010). Error bars indicate SEM. ${ }^{*} p<0.05,{ }^{* *} p<0.01,{ }^{* * *} p<0.001$.
Berkefeld and Fakler, 2008; Fakler and Adelman, 2008; Grimes et al., 2009). L-type VGCCs are highly sensitive to micromolar concentrations of DHP that, either negatively (i. e., Nife, nitrendipine) or positively (i.e., \pm Bay-K 8644), modulate their activity (Doering and Zamponi, 2003; Catterall and Few, 2008). We have previously shown that, at P9-P11, incubation of the cochlear preparation with the L-type antagonist Nife ( $3 \mu \mathrm{M})$ causes a significant increase in the quantum content of evoked release, whereas incubation with the agonist Bay-K $8644(10 \mu \mathrm{M})$ significantly reduces this parameter. This contradictory result was accounted for by the fact that, at this stage, L-type channels are not directly involved in release but are functionally coupled to the activation of $\mathrm{Ca}^{2+}$-activated BK channels that accelerate repolarization of the synaptic terminal during an action potential (Zorrilla de San Martín et al., 2010). Therefore, the block of L-type VGCCs increased release, whereas enhancement of their activity by Bay-K caused the opposite effect.

To study the role of L-type VGCCs in ACh release at the transient efferent synapse during development, we tested the effects of Nife and Bay-K on $m$ at P4 and P6-P7. At P4 and P6-P7, both the agonist $(10 \mu \mathrm{M}$ Bay-K) and the antagonist $(3 \mu \mathrm{M}$ Nife) of L-type VGCCs caused a significant increase in the quantum content of evoked release (Fig. 7; P4: $m_{\text {control }}=$ $0.12 \pm 0.04, m_{\text {Bay-K }}=0.35 \pm 0.04$, $p=0.0313 ; m_{\text {control }}=0.29 \pm 0.08, m_{\text {nife }}=$ $0.51 \pm 0.12, p=0.0078 ; \mathrm{P} 6-\mathrm{P} 7: m_{\text {control }}=$ $0.73 \pm 0.13, m_{\text {Bay-K }}=1.74 \pm 0.23$, $p=0.0018 ; m_{\text {control }}=0.72 \pm 0.15, m_{\text {nife }}=$ $1.70 \pm 0.27, p=0.0043 ; n=6-8$ cells, 6-8 mice). As shown previously (Zorrilla de San Martín et al., 2010), at P9-P11 (Fig. 7, bottom), Nife increased the quantum content of evoked release, whereas Bay-K reduced it $\left(m_{\text {control }}=1.40 \pm 0.12\right.$, $m_{\text {Bay-K }}=0.73 \pm 0.14, n=4$ cells, 4 animals, $p=9.36 \mathrm{e}^{-05} ; m_{\text {control }}=1.54 \pm$ $0.19, m_{\text {nife }}=3.20 \pm 0.70, p=0.02007$; $n=7$ cells, 7 mice). It is important to mention that transmitter release at the IHC afferent synapse is mediated by $\mathrm{Ca}_{\mathrm{v} 1.3}$ L-type VGCC (Brandt et al., 2003), so the activity of these postsynaptic channels would be modified by the presence of either Nife or Bay-K in the bath solution. However, because we voltage clamped the IHCs at $-90 \mathrm{mV}$, activation of these VGCCs upon ACh release was not taken into account because it would be negligible. The fact that both the L-type agonist and antagonist increased release from $\mathrm{P} 4$ to $\mathrm{P} 7$ was surprising and led us to evaluate whether BK channels were also involved 

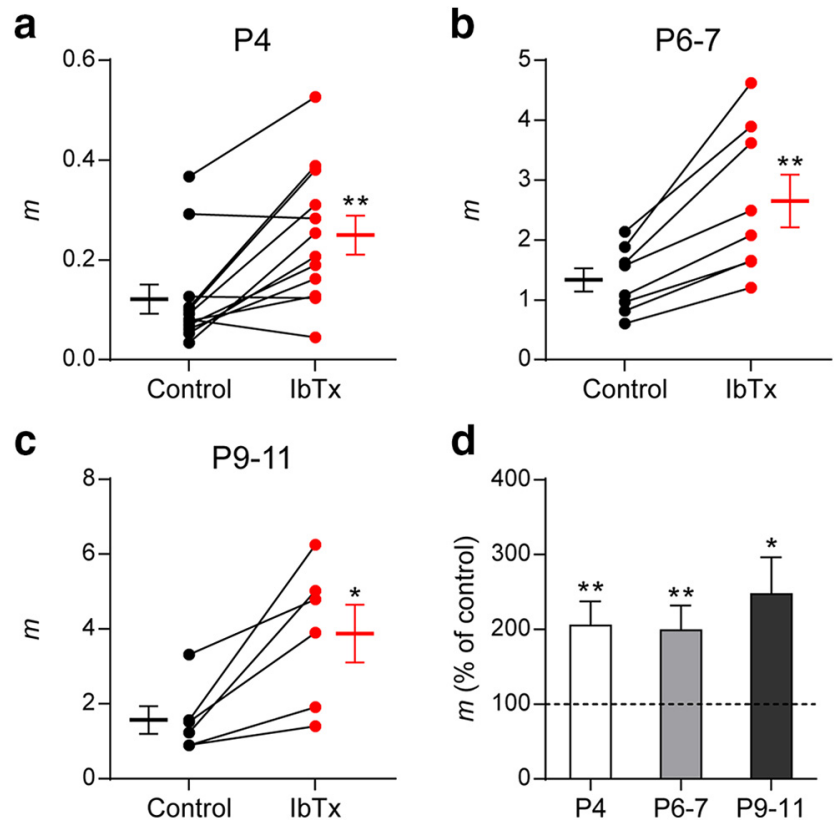

Figure 8. BK channels negatively modulate $A C h$ release at the $M O C-I H C$ synapse throughout development. $\boldsymbol{a}-\boldsymbol{c}$, Graphs showing the effect on $m$ of $100 \mathrm{~nm} \mathrm{IbTX}$, an antagonist of BK channels, in P4 (a), P6-P7 (b), and P9-P11 (c) cochlear preparations (control: black circles, treated: red circles). The mean $\pm S E M$ values of $m$ measured before and after toxin treatment are plotted to the left and right of their respective individual responses. $\boldsymbol{d}$, Bar graph summarizing the effect on $m$ of $100 \mathrm{~nm} \mathrm{IbTx}$ at the different stages of development evaluated (IbTx $m$ percentage of control: $\mathrm{P} 4=204.92 \pm 32.22 ; \mathrm{P} 6-\mathrm{P} 7=198.55 \pm 32.92 ; \mathrm{P} 9-\mathrm{P} 11=$ $247.03 \pm 49.03)$. Data from $P 9-P 11$ mice are shown for comparison and were taken from Zorrilla de San Martín et al. (2010). Error bars indicate SEM. ${ }^{*} p<0.05,{ }^{* *} p<0.01$.

in modulating the release of ACh at these two earlier stages of development.

\section{BK channels are functionally expressed at the MOC-IHC synapse from P4 to P11}

BK channels have been shown to participate in the release process due to their close association with VGCCs, as was mentioned above for L-type VGCCs (Marrion and Tavalin, 1998; Prakriya and Lingle, 1999; Sun et al., 2003; Loane et al., 2007; Marcantoni et al., 2007; Müller et al., 2007; Berkefeld and Fakler, 2008; Fakler and Adelman, 2008; Grimes et al., 2009). In hair cells from the frog sacculus, $\mathrm{Ca}^{2+}$ influx through VGCCs promotes both electrical resonance and the release of neurotransmitter due to the close association of VGCCs and BK channels near the presynaptic active zones (Roberts et al., 1990). At the frog NMJ, $\mathrm{Ca}^{2+}$ entry through N-type channels triggers the release of ACh and at the same time repolarizes the terminal membrane due to the close association of VGCCs and BK channels at the active zones (Robitaille et al., 1993a,b).

The participation of BK channels in the release process at the transient MOC-IHC synapse was evaluated by incubating the cochlear preparation with IbTx, a specific blocker of BK channels (Galvez et al., 1990). Figure 8 illustrates the effects of $100 \mathrm{~nm} \mathrm{IbTx}$ on the quantum content of ACh release at P4 (Fig. 8a,d), P6-P7 (Fig. 8b,d), and P9-P11 (Fig. 8c,d). Data from Zorrilla de San Martín et al. (2010) were tested for normal distribution, reanalyzed, and plotted for comparison with the earlier stages). Blocking BK channels with IbTx caused a strong and significant increase in evoked release at all the developmental stages studied: P4: $m_{\text {control }}=0.12 \pm 0.03, m_{\mathrm{IbTx}}=0.25 \pm 0.04, p=0.0068$. P6-P7: $m_{\text {control }}=1.34 \pm 0.19, m_{\mathrm{IbTx}}=2.65 \pm 0.44, p=0.0018$. a
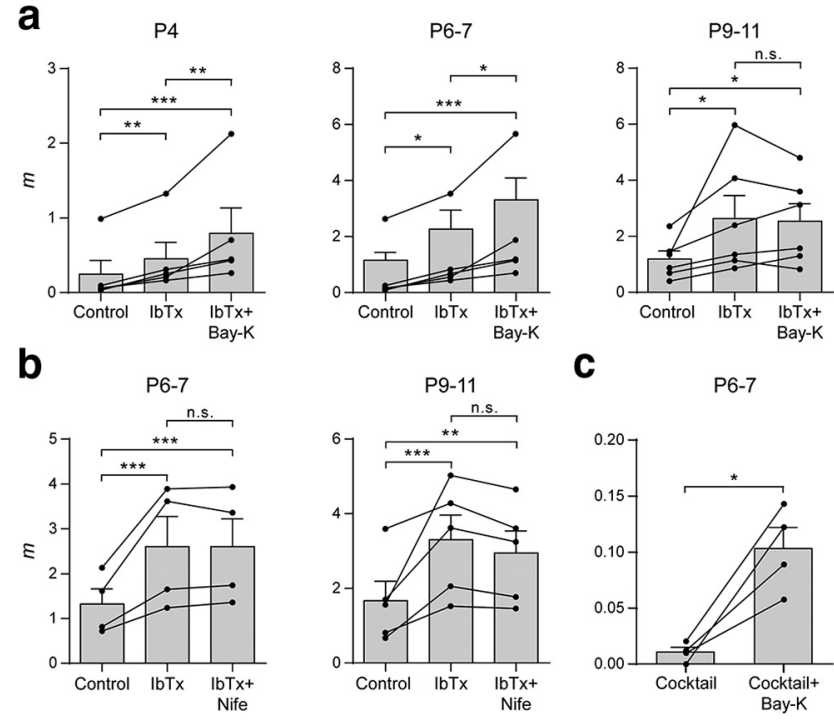

Figure 9. L-type VGCCs play a dual role on ACh release at the earlier stages of development. a, Summary plots showing that $10 \mu \mathrm{m}$ Bay-K significantly increased $m$ after blocking BK channels with $100 \mathrm{~nm}$ lbTx only in P4 and P6 - P7 IHCs. Values from each individual cell are shown as black circles. $\boldsymbol{b}$, Summary plots illustrating that $3 \mu \mathrm{m}$ Nife did not further increase $m$ after preincubating the cochlear preparations with $100 \mathrm{~nm} \mathrm{IbTx}$ at P6 -P7, as previously observed at P9-P11. C, Summary plot showing that $10 \mu \mathrm{m}$ Bay-K was still able to increase $m$ after blocking $\mathrm{P} / \mathrm{Q}-, \mathrm{R}$-, and N-type VGCCs and BK channels with a toxin mixture containing $200 \mathrm{~nm} \omega$-Aga, 500 nм $\omega$-CgTx, 500 nm SNX, and 100 nm IbTx. Data from P9-P11 mice are shown for comparison and were taken from Zorrilla de San Martín et al. (2010). Error bars indicate SEM. ${ }^{*} p<0.05$, ${ }^{* *} p<0.01,{ }^{* * *} p<0.001$.

P9-P11: $m_{\text {control }}=1.57 \pm 0.37, m_{\mathrm{IbTx}}=3.88 \pm 0.77, p=0.0313$; 6-12 cells, 6-12 mice. This result indicates that BK channels negatively modulate the release of ACh at the three stages studied.

$\mathrm{Ca}^{2+}$ influx through L-type VGCC plays a dual role at early developmental stages

We have previously shown that, at $\mathrm{P} 9-\mathrm{P} 11$, preincubation of the cochlear preparation with the BK channel blocker IbTx (100 nM) completely occludes the effects of both Nife and Bay-K (Zorrilla de San Martín et al., 2010). Therefore, we now tested the effects of Bay- $\mathrm{K}$ on the quantum content of evoked release in cochlear preparations from $\mathrm{P} 4$ and $\mathrm{P} 6-\mathrm{P} 7$ mice preincubated with IbTx (100 nM). Contrary to what was observed at P9-P11, even in the absence of functional BK channels, Bay-K significantly increased $m$ at both P4 and P6-P7 MOC-IHC synapses (P4: $m_{\text {Control }}=$ $0.25 \pm 0.19, m_{\mathrm{IbTx}}=0.45 \pm 0.22, m_{\mathrm{IbTx}+\text { Bay-K }}=0.79 \pm 0.34$, IbTx vs control $p=0.0021, \mathrm{IbTx}+\mathrm{Bay}-\mathrm{K}$ vs $\mathrm{IbTx} p=0.0021$, $\mathrm{IbTx}+\mathrm{Bay}-\mathrm{K}$ vs control $p=1.9 \mathrm{e}^{-05} ; \mathrm{P} 6-\mathrm{P} 7: m_{\text {Control }}=1.16 \pm$ $0.28, m_{\mathrm{IbTx}}=2.27 \pm 0.67, m_{\mathrm{IbTx}+\text { Bay }-\mathrm{K}}=3.31 \pm 0.78$, IbTx vs control $p=0.0248$, IbTx + Bay-K vs $\operatorname{IbTx} p=0.041$, $\mathrm{IbTx}+$ Bay-K vs control $p=9.88 \mathrm{e}^{-07} ; \mathrm{P} 9-\mathrm{P} 11: m_{\text {Control }}=1.19 \pm$ $0.29, m_{\mathrm{IbTx}}=2.63 \pm 0.82, m_{\mathrm{IbTx}+\text { Bay }-\mathrm{K}}=2.54 \pm 0.63$, IbTx vs control $p=0.0107, \mathrm{IbTx}+$ Bay-K vs IbTx $p=0.9809$, IbTx + Bay-K vs control $p=0.0189 ; n=5-6$ cells, $5-6$ mice; Fig. 9a).

Because the effects of DHPs on evoked release were similar at P4 and P6-P7 and, given the much lower number of functionally innervated IHCs found at P4, the following experiments were carried out only at P6-P7. Surprisingly, Nife ( $3 \mu \mathrm{M})$ had no effect on release at $\mathrm{P} 6-\mathrm{P} 7$ after having blocked BK channels $\left(m_{\text {Control }}=\right.$ $1.32 \pm 0.34, m_{\mathrm{IbTx}}=2.60 \pm 0.67, m_{\mathrm{IbTx}+\mathrm{Nife}}=2.60 \pm 0.62, \mathrm{IbTx}$ vs control $p=6.82 \mathrm{e}^{-06}, \mathrm{IbTx}+$ Nife vs IbTx $p=1$, IbTx + Nife vs control $p=6.86 \mathrm{e}^{-06} ; n=4$ cells, 4 mice; Fig. $9 b$ ). This lack of 

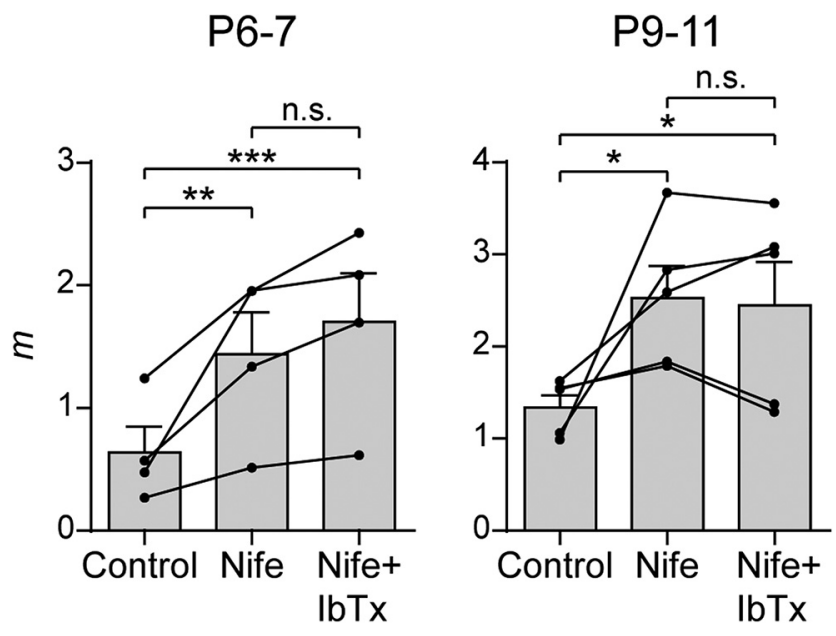

Figure 10. BK channels are activated only by $\mathrm{Ca}^{2+}$ influx through L-type VGCCs. Summary plots show that $100 \mathrm{~nm} \mathrm{lbTx}$ did not further increase $m$ after preincubating cochlear preparations with $3 \mu \mathrm{m}$ Nife at P6 -P7 (left), as described previously for P9-P11 (right) (Zorrilla de San Martín et al., 2010). Values from each individual cell are shown as black circles. Error bars indicate SEM. ${ }^{*} p<0.05,{ }^{* *} p<0.01,{ }^{* * *} p<0.001$.

effect of the L-type VGCC antagonist was the same as that observed at P9-P11 $\left(m_{\text {control }}=1.67 \pm 0.52, m_{\mathrm{IbTx}}=3.30 \pm 0.66\right.$, $m_{\mathrm{IbTx}+\mathrm{Nife}}=2.95 \pm 0.59$, control vs IbTx $p=3.47 \mathrm{e}^{-04}$, IbTx vs IbTx + Nife $p=0.6789$, control vs IbTx + Nife $p=0.0073 ; n=5$ cells, 5 mice) plotted here for comparison (Zorrilla de San Martín et al., 2010). The effect of Bay-K suggests that, at the earlier stages, L-type VGCCs are involved in supporting release. However, the lack of effect of Nife suggests the contrary.

In view of these conflicting results between the effects of Bay-K and Nife in the absence of functional BK channels (Fig. $9 a, b)$, we decided to confirm the participation of L-type VGCCs in transmitter release by testing the effects of Bay-K in the presence of P/Q-, R-, and N-type VGCC and BK channel blockers (the ion channel blocking mixture was made up of $200 \mathrm{nM} \omega$-Aga, $500 \mathrm{~nm} \omega$-CgTx, $500 \mathrm{~nm}$ SNX, and 100 nм IbTx). After preincubating the cochlear preparation with this mixture, Bay-K significantly increased $m\left(m_{\text {cocktail }}=0.011 \pm 0.004, m_{\text {cocktail }+ \text { Bay }-\mathrm{K}}=\right.$ $0.103 \pm 0.019, p=0.0152 ; n=4$ cells, 4 mice; Fig. $9 c)$. This confirms that, at $\mathrm{P} 6-\mathrm{P} 7$, under certain conditions, $\mathrm{Ca}^{2+}$ flowing in through L-type VGCCs can reach the evoked-release site machinery and support ACh release.

At P9-P11, BK channels are activated only by $\mathrm{Ca}^{2+}$ influx through L-type VGCC without the participation of $\mathrm{Ca}^{2+}$ flowing in through either P/Q- or N-type VGCCs (Zorrilla de San Martín et al., 2010). Therefore, we also tested whether this was also the case at P6-P7 by evaluating the effects of IbTx after preincubating the cochlear preparation with Nife $(3 \mu \mathrm{M})$. As illustrated in Figure 10 (P6-P7: $m_{\text {control }}=0.64 \pm 0.21, m_{\text {Nife }}=1.44 \pm 0.34$, $m_{\mathrm{Nife}+\mathrm{IbTx}}=1.70 \pm 0.39$, control vs Nife $p=0.0039$, Nife vs Nife+IbTx $p=0.8622$, control vs Nife+IbTx $p=5.66 \mathrm{e}^{-05}$; P9-P11: $m_{\text {control }}=1.34 \pm 0.13, \mathrm{~m}_{\mathrm{Nife}}=2.53 \pm 0.35, \mathrm{~m}_{\mathrm{Nife}+\mathrm{IbTx}}=$ $2.45 \pm 0.47$, control vs Nife $p=0.0174$, Nife vs Nife + IbTx $p=$ 0.9809 , control vs Nife $+\operatorname{IbTx} p=0.0294 ; n=4-5$ cells from $4-5$ mice), Nife also occluded the effects of IbTx at P6-P7 (P9-P11 values are from Zorrilla de San Martín et al., 2010, and plotted for comparison). This shows that, throughout development, BK channels at MOC-IHC synapses are only activated by $\mathrm{Ca}^{2+}$ influx through L-type VGCCs.
Effects of L-type channel modulators on $\mathrm{K}^{+}$-evoked release To further investigate whether the differential effects of the DHPs on electrically evoked ACh release during development could be related to changes in the colocalization of L-type VGCCs with respect to the release sites activated upon invasion of an action potential to the synaptic terminal, we tested the effects of Bay-K and Nife on $\mathrm{K}^{+}$-evoked release of transmitter. This type of release is independent from the generation of an action potential due to $\mathrm{Na}^{+}$channel inactivation under constant depolarization (Hodgkin and Huxley, 1952). Therefore, this experimental paradigm allowed us to evaluate the effects of L-type VGCCs modulators on a mechanistically different type of neurotransmitter release. Moreover, as demonstrated by freeze fracture experiments at the frog NMJ, transmitter release evoked by high $\mathrm{K}^{+}$occurs also at "latent or ectopic" sites lying between the "active zones" observed upon electrical stimulation (Ceccarelli et al., 1979).

Figure 11 illustrates the effects of Bay-K $(10 \mu \mathrm{M})$ and Nife (3 $\mu \mathrm{M})$ at P6-P7 (Fig. 11a,b, top) and at P9-P11 (Fig. 11a,b, bottom). In this type of release, the L-type agonist Bay-K significantly increased the frequency of sIPSCs at both ages (P6-P7 sIPSC frequency control $0.80 \pm 0.23 \mathrm{~Hz}$, sIPSC frequency Bay-K $5.65 \pm 1.56 \mathrm{~Hz}, n=6$ cells, 6 animals, $p=0.0205$; P9-P1 1 sIPSC frequency control $2.25 \pm 1.19 \mathrm{~Hz}$, sIPSC frequency Bay-K $5.98 \pm$ $1.93 \mathrm{~Hz}, p=0.0313 ; n=7$ cells, 7 mice), whereas the antagonist Nife significantly reduced it (P6-P7 sIPSC frequency control $2.69 \pm 0.90 \mathrm{~Hz}$, sIPSC frequency Nife $0.61 \pm 0.11 \mathrm{~Hz}, p=0.0156$; P9-P11 sIPSC frequency control $3.42 \pm 1.74 \mathrm{~Hz}$, sIPSC frequency Nife $1.40 \pm 0.70 \mathrm{~Hz}, p=0.0313 ; n=6-7$ cells from $6-7$ mice). This result suggests that the differences found in the effects of Bay-K on P4 and P6-P7 with respect to P9-P11 might be related to developmental changes in the localization of L-type channels with respect to the action potential evoked-neurotransmitter release machinery.

\section{Discussion}

\section{Developmental changes in the biophysical properties of ACh release}

The MOC-IHC synapse is functional from P0 to hearing onset. Both the number of functionally innervated cells and the amplitude of ACh-evoked currents significantly increase from P3 to P11, returning to very low values just after hearing onset. In addition, the $\alpha 10 \mathrm{nAChR}$ subunit and the SK2 channel, two key postsynaptic proteins, are downregulated and disappear at $\sim \mathrm{P} 14$ (Katz et al., 2004; Roux et al., 2011). We now show that, during the developmental critical period before hearing onset, dramatic presynaptic changes take place at the transient MOC-IHC synapse.

Synaptic strength significantly increased from P4 to P9-P11 due to a $5.6 \times$ increase in the quantum content with a concomitant reduction in the number of release failures. This, together with the increase in sIPSC frequency and the lack of changes in their amplitude and kinetics, support the notion that the increment in synaptic strength is of presynaptic origin (Del Castillo and Katz, 1954b). The sIPSC decay time constant is dominated by the closure kinetics of SK2 channels (Oliver et al., 2000), so as already reported (Katz et al., 2004; Roux et al., 2011), coupling between the $\alpha 9 \alpha 10 \mathrm{nAChR}$ and the SK2 channel is stable from $\mathrm{P} 4$ to P11.

Changes in quantum content were reflected in the STP pattern, which shifted from facilitation at P4 and P6-P7 to depression at P9-P11. Variations in STP during development have been observed in other systems: the visual cortex (Chen and Roper, 2004), cerebellum (Pouzat and Hestrin, 1997), hippocampus 
a
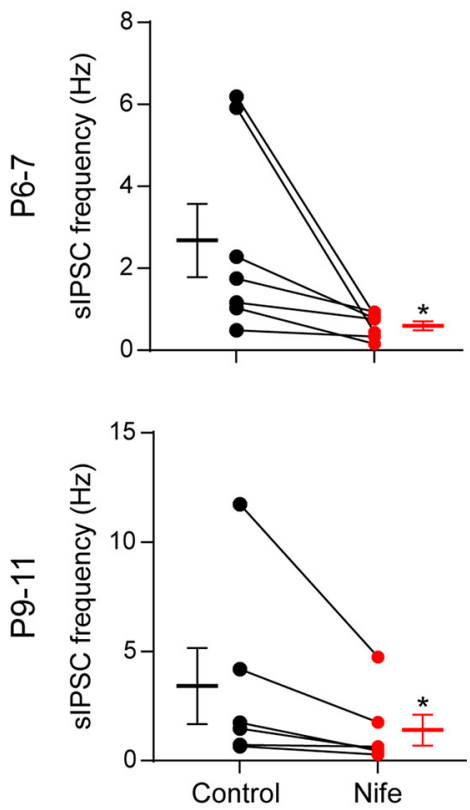
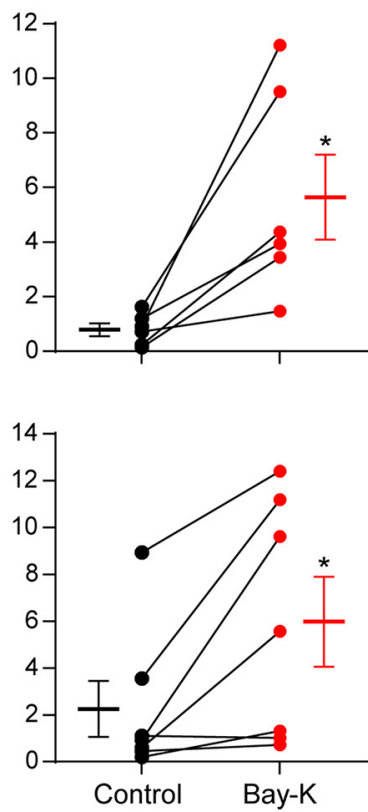

b

P6-7
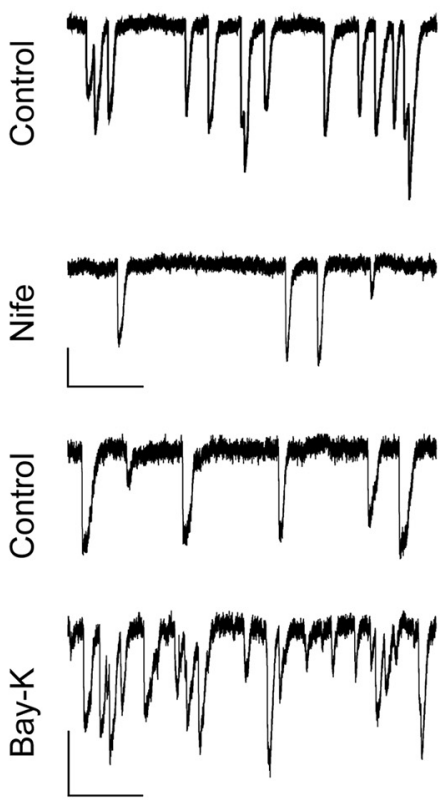

Figure 11. Effect of DHPs on transmitter release evoked by high external $\mathrm{K}^{+} . \boldsymbol{a}$, Graphs showing the effect of $3 \mu \mathrm{m}$ Nife (left) and $10 \mu \mathrm{m}$ Bay-K 8644 (right) on the frequency of sIPSCs recorded in P6-P7 IHCs (top) and P9-P11 IHCs (bottom) during application of an external solution containing 15-25 mм K ${ }^{+}$. $\boldsymbol{b}$, Representative traces recorded before and after incubation with $3 \mu \mathrm{m}$ Nife (top) and $10 \mu \mathrm{m}$ Bay-K (bottom) in P6 -P7 IHCs. Vertical scale bars, 50 pA; horizontal scale bars, 1 s. Error bars indicate SEM. ${ }^{*} p<0.05$.

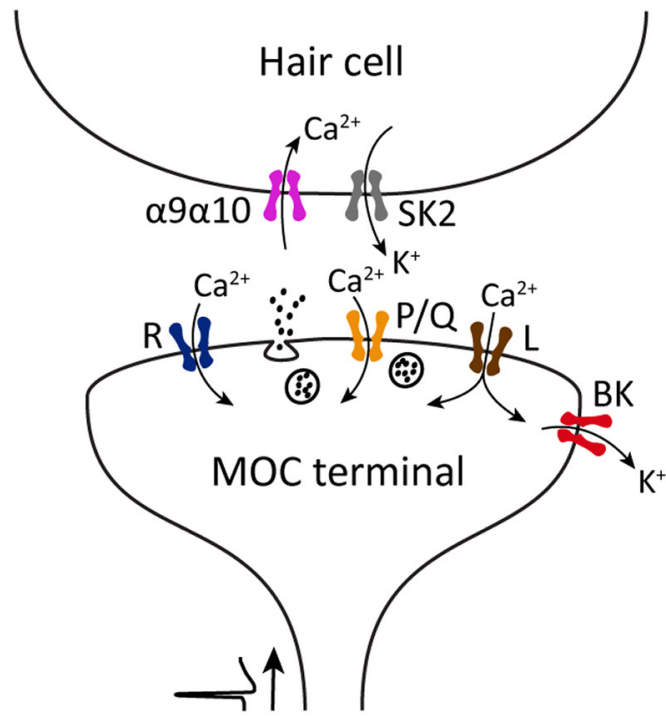

P4 and P6-7
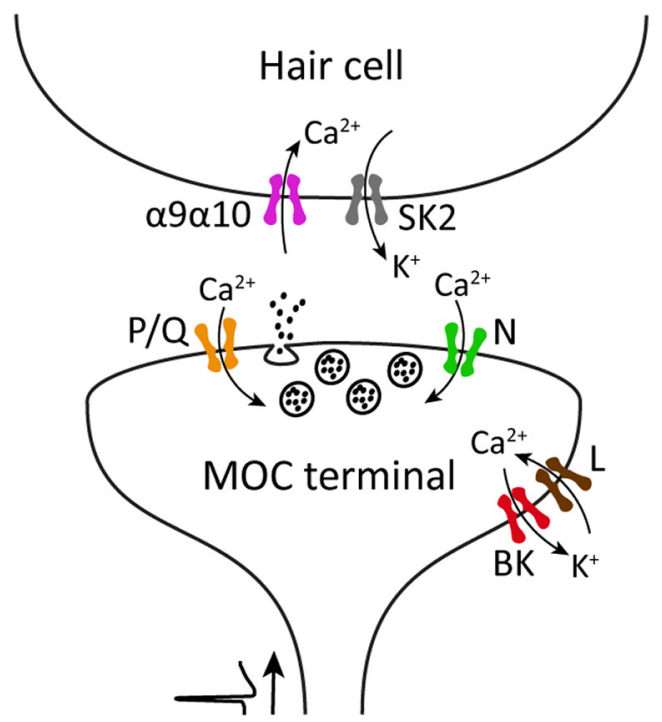

P9-11

Figure 12. Schematic representation of the ion channels that support and modulate ACh release from MOC presynaptic terminals transiently innervating the IHCs during postnatal development. After an action potential arrives to the presynaptic terminal, $\mathrm{Ca}^{2+}$ influx through P/Q-, R-, and L-type VGCCs mediate ACh release at the earlier stages of development (P4 and P6 - P7). At a later stage (P9-P11), R-type VGCCs are downregulated and N-type VGCC start contributing to the release process. Throughout this period, $\mathrm{Ca}^{2+}$ entering through L-type VGCCs exert a negative modulation on transmitter release by activating BK channels, which accelerate the repolarization of the terminal action potential, thereby reducing the amount of neurotransmitter released per nerve impulse.

(Schiess et al., 2010), and the calyx of Held (Taschenberger and von Gersdorff, 2000). Curiously, in the rat MOC-IHC synapse at $\mathrm{P} 9-\mathrm{P} 11$, facilitation of responses is observed upon highfrequency stimulation (Goutman et al., 2005), whereas in mice, we found depression under the same experimental condition. Because the quantum content at both synapses is similar $(\sim 1)$, other factors account for these species differences in STP pattern. This could include the RRP size or replenishment rate, the VGCCs supporting and/or modulating release, differential mod- ulation by BK channels (Zorrilla de San Martín et al., 2010), nitric oxide (Kong et al., 2013), and other neurotransmitter systems (Wedemeyer et al., 2013; Ye et al., 2017).

There is accumulated evidence indicating that facilitation is caused by an elevated $\left[\mathrm{Ca}^{2+}\right]_{\mathrm{i}}$ remaining from the previous stimulus (Jackman and Regehr, 2017). The relationship between the increment in the quantum content and short-term depression is usually accounted for by a greater RRP depletion due to a greater number of neurotransmitter quanta released at the first stimulus 
of the train (Zucker and Regehr, 2002). These notions are consistent with our results showing that changes in the quantum content were correlated with the STP pattern: at P9-P11, depression upon $100 \mathrm{~Hz}$ stimulation train was replaced by facilitation upon reducing $\left[\mathrm{Ca}^{2+}\right]_{\mathrm{o}}$ from 1.3 to $1.1 \mathrm{~mm}$, whereas at $\mathrm{P} 6-\mathrm{P} 7$, facilitation was replaced by depression upon raising it from 1.3 to 1.5 mM. During development, however, $P_{\text {vesicle }}$ remained constant, whereas RRP and its replenishment rate increased. Therefore, RRP depletion is not likely to be the cause of depression upon high-frequency stimulation. It has been reported that currents through P/Q-type VGCCs can either facilitate or depress upon repetitive stimulation depending on the presence of regulatory proteins (Catterall et al., 2013; Nanou and Catterall, 2018). Therefore, differences in the expression of regulatory proteins might account for the changes in STP pattern between P9-P11 and earlier developmental stages (Rosato Siri and Uchitel, 1999; Wu et al., 1999). The amount of transmitter release evoked by an action potential depends upon the size of the effective RRP and on the initial probability of release of each of the vesicles within this pool (Thanawala and Regehr, 2013). Therefore, because $P_{\text {vesicle }}$ remained constant, the increment observed in $P_{\text {success }}$ is likely to be accounted for by the increment in RRP size. This agrees with the observation that quantum content and RRP size across the three ages studied presented a similar incremental ratio (P6-P7/P4: $m=3$, RRP size = 3.6; P9-P11/P6-P7: $m=2$, RRP size $=1.7 ; \mathrm{P} 9-\mathrm{P} 11 / \mathrm{P} 4: m=5.6$, RRP size $=6.2$ ).

\section{Developmental changes in VGCCs coupled to ACh release}

We have shown that at P9-P11 transmitter release at the MOCIHC synapse is mediated by $\mathrm{Ca}^{2+}$ influx through P/Q- and N-type VGCCs (Zorrilla de San Martín et al., 2010). We now show that P/Q-type VGCCs are coupled to ACh release from P4 to P11. However, at P4 and P6-P7, N-type VGCCs do not participate in release, which is mediated by P/Q- and R-type VGCCs. In addition, at P9-P11, there is a switch from R-type to $\mathrm{N}$-type VGCCs. The participation of R-type VGCCs in ACh release from MOC fibers is in agreement with PCR analysis in the mouse cochlea (Green et al., 1996) and with immunohistochemical studies showing that $\mathrm{Ca}_{\mathrm{v}} 2.3$ (R-type) is expressed by MOC fibers from P2 to P14 (Waka et al., 2003). In addition, $\mathrm{Ca}_{\mathrm{v}} 2.1$ (P/Qtype) has been also shown by transcriptome analysis to be expressed in the mammalian inner ear (Gabashvili et al., 2007).

Developmental changes in VGCCs coupled to transmitter release have been reported both at the NMJ (Rosato Siri and Uchitel, 1999) and at central synapses (Iwasaki et al., 2000; Momiyama, 2003; Fedchyshyn and Wang, 2005). At those synapses, both P/Q- and N-type VGCCs are coupled to the release process at early stages of maturation. In adults, P/Q-type channels are the predominant VGCCs coupled to transmitter release. The contribution of N-type VGCCs either completely disappears during maturation in the NMJ (Rosato Siri and Uchitel, 1999), GABAergic synapses of the cerebellum and thalamus (Iwasaki et al., 2000), and glutamatergic synapses of the calyx of Held (Fedchyshyn and Wang, 2005) or significantly diminishes in GABAergic striatal synapses (Momiyama, 2003). Curiously, at the MOC-IHC synapse, N-type VGCCs do not mediate transmitter release at the earliest developmental stages.

At immature neuromuscular and calyx of Held synapses, P/Qtype VGCCs are closer to the calcium sensor than N-type VGCCs and therefore it has been suggested that this spatial distribution accounts for the greater efficacy of P/Q-type channels in coupling to release (Rosato Siri and Uchitel, 1999; Wu et al., 1999). In this respect, the observation that $P_{\text {vesicle }}$ did not change with matura- tion of the MOC-IHC synapse might be related to the fact that $\mathrm{P} / \mathrm{Q}$-type channels mediate this process across all of the developmental stages studied. Therefore, at the MOC-IHC synapse, P/Qtype channels might be closer to the release sites compared with the other VGCCs that also support this process and thus be the main regulators of release probability.

\section{Dual role of L-type VGGCs at early stages of development}

Based on the effects of L-type channel modulators and the BK channel antagonist on transmitter release at the MOC-IHC synapse, we show that, at the early stages of development, $\mathrm{Ca}^{2+}$ influx through L-type VGCCs has a dual role. It exerts a negative feedback on transmitter release because it activates BK channels, which accelerate terminal membrane repolarization (Storm, 1987; Berkefeld and Fakler, 2008), thereby reducing the amount of transmitter released per action potential (Roberts et al., 1990; Robitaille et al., 1993a,b; Raffaelli et al., 2004; Zorrilla de San Martín et al., 2010). Conversely, under certain conditions, as observed in the presence of Bay- $\mathrm{K}$, which increases the mean open time of L-type VGCCs (Bechem and Hoffmann, 1993), or when BK channels and all other VGGCs are blocked, $\mathrm{Ca}^{2+}$ influx through L-type VGCCs can reach the release sites and contribute to ACh release.

The dual role of VGCCs on transmitter release has also been demonstrated at the frog NMJ for N-type VGCCs, where the entry of $\mathrm{Ca}^{2+}$ that triggers release also activates $\mathrm{BK}$ channels (Robitaille et al., 1993a; Robitaille et al., 1993b). The fact that, as of P4-P7, $\mathrm{Ca}^{2+}$ influx through L-type VGGCs, apart from activating $B K$ channels, can also reach the release sites, whereas at $\mathrm{P} 9-\mathrm{P} 11$, it cannot strongly suggests that at the early stages there is less compartmentalization of the presynaptic proteins that compose the action potential evoked-release machinery. Even though other experimental approaches should be used to give further support to this hypothesis at the MOC-IHC synapse, spatial tightening during development between the proteins involved in the release process has been described both at the calyx of Held synapse (Fedchyshyn and Wang, 2005; Leão and von Gersdorff, 2009) and at cerebellar cortical synapses (Baur et al., 2015).

\section{Conclusions}

Variation in the expression and localization of ion channels involved in synaptic transmission at the MOC-IHC synapse, together with changes in synaptic strength (summarized in Fig. 12) underlie developmental changes in STP. Moreover, when MOC fibers fire at high rate, facilitation or depression of the MOC-IHC synapse (depending on developmental stage) might lead to the fine tuning of IHC action potential frequency pattern (Goutman et al., 2005; Johnson et al., 2011; Sendin et al., 2014), thus regulating signaling at the first synapse of the auditory pathway during its establishment.

\section{References}

Art JJ, Fettiplace R, Fuchs PA (1984) Synaptic hyperpolarization and inhibition of turtle cochlear hair cells. J Physiol 356:525-550.

Ballestero J, Zorrilla de San Martín J, Goutman J, Elgoyhen AB, Fuchs PA, Katz E (2011) Short-term synaptic plasticity regulates the level of olivocochlear inhibition to auditory hair cells. J Neurosci 31:14763-14774.

Baur D, Bornschein G, Althof D, Watanabe M, Kulik A, Eilers J, Schmidt H (2015) Developmental tightening of cerebellar cortical synaptic influxrelease coupling. J Neurosci 35:1858-1871.

Bechem M, Hoffmann H (1993) The molecular mode of action of the ca agonist (-) BAY K 8644 on the cardiac ca channel. Pflugers Arch 424:343353.

Berkefeld H, Fakler B (2008) Repolarizing responses of BKCa-cav com- 
plexes are distinctly shaped by their cav subunits. J Neurosci 28:8238-8245.

Bourinet E, Stotz SC, Spaetgens RL, Dayanithi G, Lemos J, Nargeot J, Zamponi GW (2001) Interaction of SNX482 with domains III and IV inhibits activation gating of alpha $(1 \mathrm{E})(\mathrm{Ca}(\mathrm{V}) 2.3)$ calcium channels. Biophys J 81:79-88.

Brandt A, Striessnig J, Moser T (2003) CaV1.3 channels are essential for development and presynaptic activity of cochlear inner hair cells. J Neurosci 23:10832-10840.

Catterall WA (1998) Structure and function of neuronal Ca2+ channels and their role in neurotransmitter release. Cell Calcium 24:307-323.

Catterall WA (2011) Voltage-gated calcium channels. Cold Spring Harb Perspect Biol 3:a003947.

Catterall WA, Few AP (2008) Calcium channel regulation and presynaptic plasticity. Neuron 59:882-901.

Catterall WA, Leal K, Nanou E (2013) Calcium channels and short-term synaptic plasticity. J Biol Chem 288:10742-10749.

Ceccarelli B, Grohovaz F, Hurlbut WP (1979) Freeze-fracture studies of frog neuromuscular junctions during intense release of neurotransmitter. II. effects of electrical stimulation and high potassium. J Cell Biol 81:178-192.

Chanaday NL, Kavalali ET (2018) Presynaptic origins of distinct modes of neurotransmitter release. Curr Opin Neurobiol 51:119-126.

Chen HX, Roper SN (2004) Tonic activity of metabotropic glutamate receptors is involved in developmental modification of short-term plasticity in the neocortex. J Neurophysiol 92:838-844.

Clause A, Kim G, Sonntag M, Weisz CJ, Vetter DE, Rúbsamen R, Kandler K (2014) The precise temporal pattern of prehearing spontaneous activity is necessary for tonotopic map refinement. Neuron 82:822-835.

Clause A, Lauer AM, Kandler K (2017) Mice lacking the Alpha9 subunit of the nicotinic acetylcholine receptor exhibit deficits in frequency difference limens and sound localization. Front Cell Neurosci 11:167.

Del Castillo J, Katz B (1954a) Statistical factors involved in neuromuscular facilitation and depression. J Physiol 124:574-585.

Del Castillo J, Katz B (1954b) Quantal components of the end-plate potential. J Physiol 124:560-573.

Dodge FA Jr, Rahamimoff R (1967) Co-operative action a calcium ions in transmitter release at the neuromuscular junction. J Physiol 193:419432.

Doering CJ, Zamponi GW (2003) Molecular pharmacology of high voltageactivated calcium channels. J Bioenerg Biomembr 35:491-505.

Dulon D, Lenoir M (1996) Cholinergic responses in developing outer hair cells of the rat cochlea. Eur J Neurosci 8:1945-1952.

Elgoyhen AB, Katz E (2012) The efferent medial olivocochlear-hair cell synapse. J Physiol Paris 106:47-56.

Elgoyhen AB, Johnson DS, Boulter J, Vetter DE, Heinemann S (1994) a9: an acetylcholine receptor with novel pharmacological properties expressed in rat cochlear hair cells. Cell 79:705-715.

Elgoyhen AB, Vetter DE, Katz E, Rothlin CV, Heinemann SF, Boulter J (2001) alpha10: a determinant of nicotinic cholinergic receptor function in mammalian vestibular and cochlear mechanosensory hair cells. Proc Natl Acad Sci U S A 98:3501-3506.

Fakler B, Adelman JP (2008) Control of K(Ca) channels by calcium nano/ microdomains. Neuron 59:873-881.

Fedchyshyn MJ, Wang LY (2005) Developmental transformation of the release modality at the calyx of held synapse. J Neurosci 25:4131-4140.

Fioravante D, Regehr WG (2011) Short-term forms of presynaptic plasticity. Curr Opin Neurobiol 21:269-274.

Gabashvili IS, Sokolowski BH, Morton CC, Giersch AB (2007) Ion channel gene expression in the inner ear. J Assoc Res Otolaryngol 8:305-328.

Galvez A, Gimenez-Gallego G, Reuben JP, Roy-Contancin L, Feigenbaum P, Kaczorowski GJ, Garcia ML (1990) Purification and characterization of a unique, potent, peptidyl probe for the high conductance calciumactivated potassium channel from venom of the scorpion Buthus tamulus. J Biol Chem 265:11083-11090.

Glowatzki E, Fuchs PA (2000) Cholinergic synaptic inhibition of inner hair cells in the neonatal mammalian cochlea. Science 288:2366-2368.

Gómez-Casati ME, Fuchs PA, Elgoyhen AB, Katz E (2005) Biophysical and pharmacological characterization of nicotinic cholinergic receptors in rat cochlear inner hair cells. J Physiol 566:103-118.

Goutman JD, Fuchs PA, Glowatzki E (2005) Facilitating efferent inhibition of inner hair cells in the cochlea of the neonatal rat. J Physiol 566:49-59.
Green GE, Khan KM, Beisel DW, Drescher MJ, Hatfield JS, Drescher DG (1996) Calcium channel subunits in the mouse cochlea. J Neurochem 67:37-45.

Grimes WN, Li W, Chávez AE, Diamond JS (2009) BK channels modulate pre- and postsynaptic signaling at reciprocal synapses in retina. Nat Neurosci 12:585-592.

Guinan JJ (2011) Physiology of the medial and lateral olivocochlear systems. In: Auditory and vestibular efferents (Ryugo DK, Fay RR, Popper AN, eds), pp 39-81. New York: Springer.

Hodgkin AL, Huxley AF (1952) The dual effect of membrane potential on sodium conductance in the giant axon of loligo. J Physiol 116:497-506.

Hudspeth AJ (1997) How hearing happens. Neuron 19:947-950.

Iwasaki S, Momiyama A, Uchitel OD, Takahashi T (2000) Developmental changes in calcium channel types mediating central synaptic transmission. J Neurosci 20:59-65.

Jackman SL, Regehr WG (2017) The mechanisms and functions of synaptic facilitation. Neuron 94:447-464.

Johnson SL, Eckrich T, Kuhn S, Zampini V, Franz C, Ranatunga KM, Roberts TP, Masetto S, Knipper M, Kros CJ, Marcotti W (2011) Positiondependent patterning of spontaneous action potentials in immature cochlear inner hair cells. Nat Neurosci 14:711-717.

Johnson SL, Wedemeyer C, Vetter DE, Adachi R, Holley MC, Elgoyhen AB, Marcotti W (2013) Cholinergic efferent synaptic transmission regulates the maturation of auditory hair cell ribbon synapses. Open Biol 3:130163.

Kaeser PS, Regehr WG (2014) Molecular mechanisms for synchronous, asynchronous, and spontaneous neurotransmitter release. Annu Rev Physiol 76:333-363.

Katz B, Miledi R (1968) The Role of Calcium in Neuromuscular Facilitation. J Physiol 195: 481-492.

Katz E, Ferro PA, Weisz G, Uchitel OD (1996) Calcium channels involved in synaptic transmission at the mature and regenerating mouse neuromuscular junction. J Physiol 497:687-697.

Katz E, Protti DA, Ferro PA, Rosato Siri MD, Uchitel OD (1997) Effects of $\mathrm{Ca} 2+$ channel blocker neurotoxins on transmitter release and presynaptic currents at the mouse neuromuscular junction. Br J Pharmacol 121: 1531-1540.

Katz E, Elgoyhen AB, Gómez-Casati ME, Knipper M, Vetter DE, Fuchs PA, Glowatzki E (2004) Developmental regulation of nicotinic synapses on cochlear inner hair cells. J Neurosci 24:7814-7820.

Katz E, Elgoyhen AB, Fuchs P (2011) Cholinergic inhibition of hair cells. In: Auditory and vestibular efferents (Ryugo DK, Fay RR, Popper AN, eds), pp 103-133. New York: Springer.

Kong JH, Zachary S, Rohmann KN, Fuchs PA (2013) Retrograde facilitation of efferent synapses on cochlear hair cells. J Assoc Res Otolaryngol 14:1727.

Leão RM, von Gersdorff H (2009) Synaptic vesicle pool size, release probability and synaptic depression are sensitive to $\mathrm{Ca} 2+$ buffering capacity in the developing rat calyx of held. Braz J Med Biol Res 42:94-104.

Liberman MC, Dodds LW, Pierce S (1990) Afferent and efferent innervation of the cat cochlea: quantitative analysis with light and electron microscopy. J Comp Neurol 301:443-460.

Loane DJ, Lima PA, Marrion NV (2007) Co-assembly of N-type Ca2+ and BK channels underlies functional coupling in rat brain. J Cell Sci 120:985995.

Marcantoni A, Baldelli P, Hernandez-Guijo JM, Comunanza V, Carabelli V, Carbone E (2007) L-type calcium channels in adrenal chromaffin cells: role in pace-making and secretion. Cell Calcium 42:397-408.

Marcotti W, Johnson SL, Holley MC, Kros CJ (2003) Developmental changes in the expression of potassium currents of embryonic, neonatal and mature mouse inner hair cells. J Physiol 548:383-400.

Marrion NV, Tavalin SJ (1998) Selective activation of Ca2+-activated K+ channels by co-localized Ca2 + channels in hippocampal neurons. Nature 395:900-905.

Mintz IM, Bean BP (1993) Block of calcium channels in rat neurons by synthetic omega-aga-IVA. Neuropharmacology 32:1161-1169.

Moglie MJ, Fuchs PA, Elgoyhen AB, Goutman JD (2018) Compartmentalization of antagonistic $\mathrm{Ca}(2+)$ signals in developing cochlear hair cells. Proc Natl Acad Sci U S A 115:E2095-E2104.

Momiyama T (2003) Parallel decrease in omega-conotoxin-sensitive transmission and dopamine-induced inhibition at the striatal synapse of developing rats. J Physiol 546:483-490.

Müller A, Kukley M, Uebachs M, Beck H, Dietrich D (2007) Nanodomains 
of single $\mathrm{Ca} 2+$ channels contribute to action potential repolarization in cortical neurons. J Neurosci 27:483-495.

Nanou E, Catterall WA (2018) Calcium channels, synaptic plasticity, and neuropsychiatric disease. Neuron 98:466-481.

Neher E (2015) Merits and limitations of vesicle pool models in view of heterogeneous populations of synaptic vesicles. Neuron 87:1131-1142.

Newcomb R, Szoke B, Palma A, Wang G, Chen Xh, Hopkins W, Cong R, Miller J, Urge L, Tarczy-Hornoch K, Loo JA, Dooley DJ, Nadasdi L, Tsien RW, Lemos J, Miljanich G (1998) Selective peptide antagonist of the class E calcium channel from the venom of the tarantula Hysterocrates gigas. Biochemistry 37:15353-15362.

Oliveira L, Timóteo MA, Correia-de-Sá P (2004) Tetanic depression is overcome by tonic adenosine $\mathrm{A}(2 \mathrm{~A})$ receptor facilitation of $\mathrm{L}$-type $\mathrm{Ca}(2+)$ influx into rat motor nerve terminals. J Physiol 560:157-168.

Olivera BM, Miljanich GP, Ramachandran J, Adams ME (1994) Calcium channel diversity and neurotransmitter release: the omega-conotoxins and omega-agatoxins. Annu Rev Biochem 63:823-867.

Oliver D, Klöcker N, Schuck J, Baukrowitz T, Ruppersberg JP, Fakler B (2000) Gating of Ca2+-activated K+ channels controls fast inhibitory synaptic transmission at auditory outer hair cells. Neuron 26:595-601.

Plant TD, Schirra C, Katz E, Uchitel OD, Konnerth A (1998) Single-cell RT-PCR and functional characterization of $\mathrm{Ca} 2+$ channels in motoneurons of the rat facial nucleus. J Neurosci 18:9573-9584.

Pouzat C, Hestrin S (1997) Developmental regulation of basket/stellate cell$>$ Purkinje cell synapses in the cerebellum. J Neurosci 17:9104-9112.

Prakriya M, Lingle CJ (1999) BK channel activation by brief depolarizations requires $\mathrm{Ca} 2+$ influx through $\mathrm{L}$ - and Q-type $\mathrm{Ca} 2+$ channels in rat chromaffin cells. J Neurophysiol 81:2267-2278.

R Core Team (2008) R: A language and environment for statistical computing. Vienna: R Foundation for Statistical Computing.

Raffaelli G, Saviane C, Mohajerani MH, Pedarzani P, Cherubini E (2004) BK potassium channels control transmitter release at CA3-CA3 synapses in the rat hippocampus. J Physiol 557:147-157.

Regehr WG (2012) Short-term presynaptic plasticity. Cold Spring Harb Perspect Biol 4:a005702.

Reid CA, Bekkers JM, Clements JD (2003) Presynaptic Ca2+ channels: a functional patchwork. Trends Neurosci 26:683-687.

Roberts WM, Jacobs RA, Hudspeth AJ (1990) Colocalization of ion channels involved in frequency selectivity and synaptic transmission at presynaptic active zones of hair cells. J Neurosci 10:3664-3684.

Robitaille R, Adler EM, Charlton MP (1993a) Calcium channels and calcium-gated potassium channels at the frog neuromuscular junction. J Physiol Paris 87:15-24.

Robitaille R, Garcia ML, Kaczorowski GJ, Charlton MP (1993b) Functional colocalization of calcium and calcium-gated potassium channels in control of transmitter release. Neuron 11:645-655.

Rosato Siri MD, Uchitel OD (1999) Calcium channels coupled to neurotransmitter release at neonatal rat neuromuscular junctions. J Physiol 514:533-540.

Roux I, Wersinger E, McIntosh JM, Fuchs PA, Glowatzki E (2011) Onset of cholinergic efferent synaptic function in sensory hair cells of the rat cochlea. J Neurosci 31:15092-15101.

Scheuss V, Schneggenburger R, Neher E (2002) Separation of presynaptic and postsynaptic contributions to depression by covariance analysis of successive EPSCs at the calyx of held synapse. J Neurosci 22:728-739.

Schiess AR, Scullin C, Partridge LD (2010) Maturation of schaffer collateral synapses generates a phenotype of unreliable basal evoked release and very reliable facilitated release. Eur J Neurosci 31:1377-1387.

Schneggenburger R, Meyer AC, Neher E (1999) Released fraction and total size of a pool of immediately available transmitter quanta at a calyx synapse. Neuron 23:399-409.
Sendin G, Bourien J, Rassendren F, Puel JL, Nouvian R (2014) Spatiotemporal pattern of action potential firing in developing inner hair cells of the mouse cochlea. Proc Natl Acad Sci U S A 111:1999-2004.

Simmons DD (2002) Development of the inner ear efferent system across vertebrate species. J Neurobiol 53:228-250.

Simmons DD, Mansdorf NB, Kim JH (1996) Olivocochlear innervation of inner and outer hair cells during postnatal maturation: evidence for a waiting period. J Comp Neurol 370:551-562.

Storm JF (1987) Action potential repolarization and a fast afterhyperpolarization in rat hippocampal pyramidal cells. J Physiol 385: 733-759.

Sugiura Y, Ko CP (1997) Novel modulatory effect of L-type calcium channels at newly formed neuromuscular junctions. J Neurosci 17:1101-1111.

Sun X, Gu XQ, Haddad GG (2003) Calcium influx via L- and N-type calcium channels activates a transient large-conductance $\mathrm{Ca} 2+$-activated $\mathrm{K}+$ current in mouse neocortical pyramidal neurons. J Neurosci 23:3639-3648.

Taschenberger H, von Gersdorff H (2000) Fine-tuning an auditory synapse for speed and fidelity: developmental changes in presynaptic waveform, EPSC kinetics, and synaptic plasticity. J Neurosci 20:9162-9173.

Taschenberger H, Scheuss V, Neher E (2005) Release kinetics, quantal parameters and their modulation during short-term depression at a developing synapse in the rat CNS. J Physiol 568:513-537.

Thanawala MS, Regehr WG (2013) Presynaptic calcium influx controls neurotransmitter release in part by regulating the effective size of the readily releasable pool. J Neurosci 33:4625-4633.

Valera AM, Doussau F, Poulain B, Barbour B, Isope P (2012) Adaptation of granule cell to Purkinje cell synapses to high-frequency transmission. J Neurosci 32:3267-3280

Waka N, Knipper M, Engel J (2003) Localization of the calcium channel subunits Cav1.2 (alpha1C) and Cav2.3 (alpha1E) in the mouse organ of Corti. Histol Histopathol 18:1115-1123.

Wedemeyer C, Zorrilla de San Martín J, Ballestero J, Gómez-Casati ME, Torbidoni AV, Fuchs PA, Bettler B, Elgoyhen AB, Katz E (2013) Activation of presynaptic $\operatorname{GABA}(\mathrm{B}(1 \mathrm{a}, 2))$ receptors inhibits synaptic transmission at mammalian inhibitory cholinergic olivocochlear-hair cell synapses. J Neurosci 33:15477-15487.

Wedemeyer C, Vattino LG, Moglie MJ, Ballestero J, Maison SF, Di Guilmi MN, Taranda J, Liberman MC, Fuchs PA, Katz E, Elgoyhen AB (2018) A gain-of-function mutation in the alpha9 nicotinic acetylcholine receptor alters medial olivocochlear efferent short-term synaptic plasticity. J Neurosci 38:3939-3954.

Wersinger E, Fuchs PA (2011) Modulation of hair cell efferents. Hear Res 279:1-12.

Wersinger E, McLean WJ, Fuchs PA, Pyott SJ (2010) BK channels mediate cholinergic inhibition of high frequency cochlear hair cells. PLoS One 5:e13836.

Wu LG, Westenbroek RE, Borst JG, Catterall WA, Sakmann B (1999) Calcium channel types with distinct presynaptic localization couple differentially to transmitter release in single calyx-type synapses. J Neurosci 19:726-736.

Ye Z, Goutman JD, Pyott SJ, Glowatzki E (2017) mGluR1 enhances efferent inhibition of inner hair cells in the developing rat cochlea. J Physiol 595:3483-3495.

Zorrilla de San Martín J, Pyott S, Ballestero J, Katz E (2010) Ca(2+) and $\mathrm{Ca}(2+)$-activated $\mathrm{K}(+)$ channels that support and modulate transmitter release at the olivocochlear efferent-inner hair cell synapse. J Neurosci 30:12157-12167.

Zucker RS, Regehr WG (2002) Short-term synaptic plasticity. Annu Rev Physiol 64:355-405. 